\title{
Dermatophytes et dermatophytoses
}

\author{
D. Chabasse, N. Contet-Audonneau
}

Les dermatophytes sont des champignons filamenteux ubiquitaires appartenant aux genres Microsporum, Trichophyton et Epidermophyton. Par leur reproduction sexuée ils sont affiliés aux Ascomycètes, au genre Arthroderma et à l'ordre des Onygénales. Bien adaptés à la vie parasitaire, ils présentent une forte affinité pour la kératine et déterminent chez l'homme et l'animal diverses lésions cutanées appelées dermatophytoses ou dermatophyties. Les dermatophytoses sont les mycoses cutanées les plus fréquentes chez l'homme. Elles sont responsables de lésions superficielles, de la peau glabre, des paumes et plantes des pieds, des plis (intertrigos), des cheveux ou des poils (teignes tondantes folliculites, kérions), ainsi que des lésions unguéales (onyxis). Les dermatophytoses sont en général bénignes chez un sujet immunocompétent et évoluent souvent sur un mode chronique et volontiers récidivant. Lors d'une déficience du terrain (contexte d'immunosuppression) le derme peut être envahi et même les viscères comme dans la situation extrême d'une maladie dermatophytique. Les dermatophytoses prennent des aspects cliniques très variés, parfois atypiques simulant une autre affection dermatologique, d'où l'importance du diagnostic étiologique avec prélèvement à visée mycologique au niveau des lésions qui doit être réalisé (en particulier dans les onychomycoses) avant la mise en œuvre d'un traitement par voie générale. Le traitement actuel est bien codifié, lorsqu'il s'agit d'une teigne la griséofulvine est privilégiée, lors d'une atteinte unguéale la terbinafine est la molécule de choix. Les traitements locaux font appel surtout aux azolés, parfois à la terbinafine et à la ciclopiroxolamine. La prophylaxie repose sur des mesures d'hygiène individuelle et collective, notamment au niveau des établissements sportifs (piscines, douches). En cas de teigne anthropophile, l'éviction scolaire, inutile si la contamination est d'origine animale, n'est plus obligatoire si le traitement est institué et bien suivi.

Mots clés : Dermatophytes ; Dermatophytoses ; Teignes ; Intertrigos ; Onyxis ; Diagnostic mycologique

Plan

- Définition. Généralités 1

- Rappel historique et épidémiologique

- Origine de la contamination et espèces incriminées Dermatophytes anthropophiles

Dermatophytes zoophiles

Dermatophytes géophiles

- Aspects cliniques des dermatophytoses et principaux

diagnostics différentiels

Teignes du cuir chevelu

Atteintes de la peau glabre

Atteintes des plis ou intertrigos

Atteintes des paumes des mains

Atteintes des ongles ou onyxis à dermatophytes

Dermatophytoses plus rares

Atteintes de nature allergique appelées « dermatophytides »

- Diagnostic au laboratoire

Introduction, démarche diagnostique

Prélèvement

Examen direct

Examen anatomopathologique

Cultures

Apport de la biologie moléculaire

Antifongigramme

\author{
- Thérapeutique des dermatophytoses et prévention \\ Antifongiques utilisés actifs sur les dermatophytes \\ Thérapeutiques alternatives \\ Indications générales \\ - Conclusion
}

\section{- Définition. Généralités}

Les dermatophytes sont des champignons filamenteux, au mycélium cloisonné produisant des spores (macroconidies, microconidies et chlamydospores). Ils appartiennent aux genres Microsporum, Trichophyton et Epidermophyton. Par leur reproduction sexuée ils sont affiliés aux Ascomycètes, au genre Arthroderma et à l'ordre des Onygénales [1]. Cosmopolites, ils sont bien adaptés à la vie parasitaire en assimilant la kératine humaine et animale. Les dermatophytes ont trois origines : tellurique, animale et humaine (Fig. 1). Les études phylogéniques récentes montrent que les espèces pathogènes rencontrées chez l'homme descendent d'espèces issues du sol. Le passage du sol à l'animal, puis de l'animal à l'homme semble être l'évolution phylogénique naturelle de ces champignons [2].

Les dermatophytes sont à l'origine de lésions chez l'homme appelées dermatophytoses. Ce sont les mycoses cutanées les plus fréquentes ${ }^{[3]}$. Elles touchent la peau (épiderme) et les phanères 


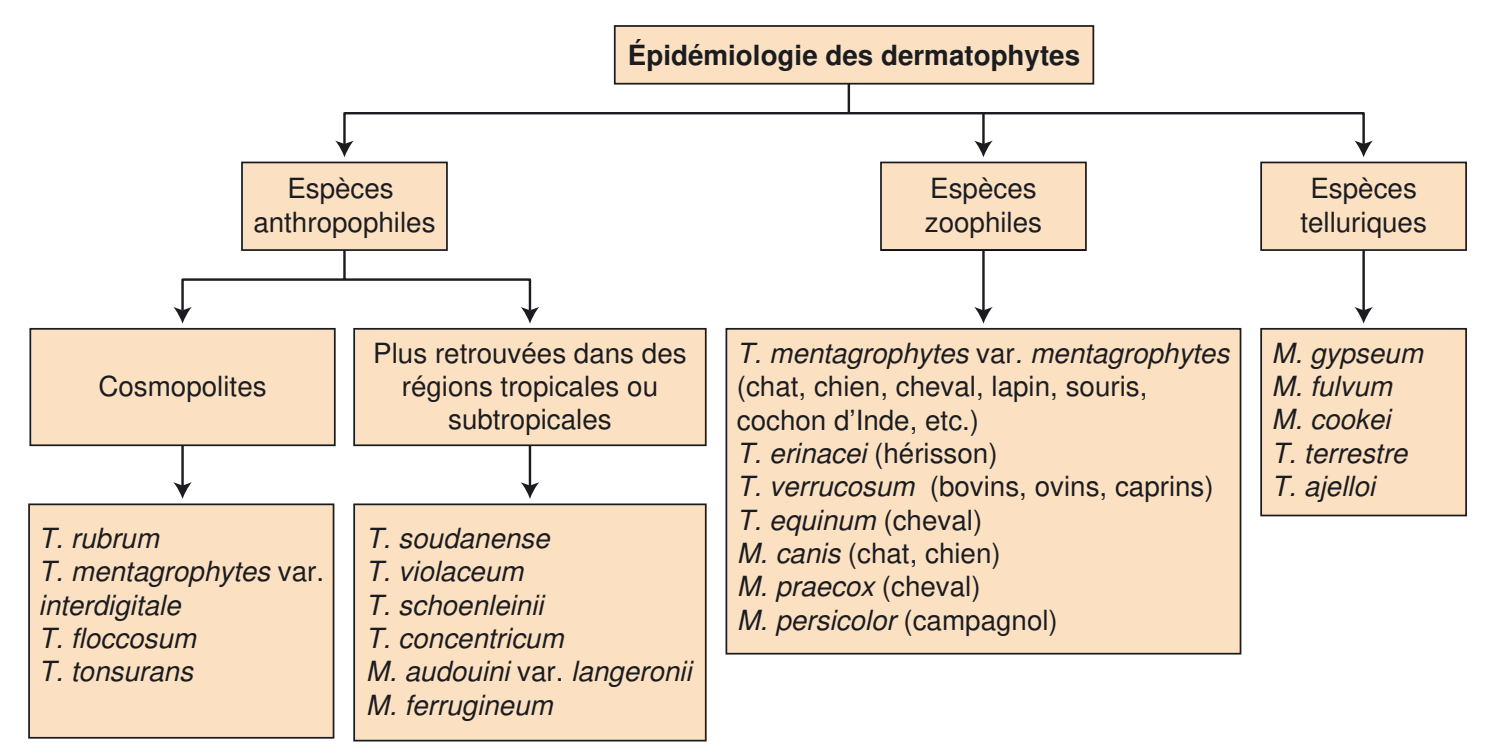

Figure 1. Origine des dermatophytes. $\mathrm{T}$ : Trichophyton; $\mathrm{M}:$ Microsporum.

(cheveux, poils, ongles) et très exceptionnellement les muqueuses, les plis, les tissus sous-cutanés (granulomes, mycétomes) ou les viscères (maladie dermatophytique). Les dermatophytoses évoluent chez l'homme selon un mode chronique et volontiers récidivant, elles prennent des aspects cliniques très variés, d'où l'importance du prélèvement mycologique et du diagnostic qui doit être systématique avant la mise en œuvre du traitement spécifique.

\section{Rappel historique et épidémiologique}

Les dermatophytoses sont des motifs fréquents de consultation, notamment en dermatologie mais aussi chez les généralistes. En France métropolitaine, jusqu'au début du $\mathrm{xx}^{\mathrm{e}}$ siècle dominaient les teignes du cuir chevelu, dues à des espèces anthropophiles (Microsporum audouinii, Trichophyton tonsurans), contagieuses, et responsables d'épidémies en milieu urbain, notamment scolaire. C'est toujours le cas aujourd'hui pour les pays économiquement pauvres où ces mycoses non traitées sont largement répandues chez les enfants [4,5]. À partir des années 1960, en France métropolitaine, et ceci grâce à l'élévation de notre niveau de vie, de notre couverture sociale et de l'efficacité de la griséofulvine (le traitement de référence), ces teignes anthropophiles autochtones sont devenues rares. Elles ont laissé la place aux teignes d'origine animale (ou zoophile). C'est ainsi que Microsporum canis, parasite du chien et du chat, est devenu dans les années 1980 le premier agent de teigne ${ }^{[6-8]}$. Depuis, le phénomène s'est amplifié avec l'engouement pour les animaux familiers (chat, chien) et le déplacement du citadin vers les campagnes avec par exemple le développement des sports équestres. Cependant, depuis ces dernières années on assiste à un retour des teignes anthropophiles en milieu urbain (notamment M. audouinii var. langeronii [9] et Trichophyton soudanense) dues aux flux migratoires des populations d'immigrés venues d'Afrique noire, des pays du Maghreb, des Caraïbes et à un degré moindre d'Asie [10]. À cela il convient d'ajouter l'augmentation des adoptions d'enfants issus de régions tropicales souvent porteurs de teignes à leur arrivée. On observe aussi le retour de $T$. tonsurans à l'origine de teignes et de dermatophytoses cutanées dans les écoles depuis $2006^{[11-13] . ~}$

À côté des teignes il faut mettre l'accent sur les dermatophytoses de la peau, des plis [14] et surtout des ongles (en particulier des pieds) qui occupent désormais le principal motif de consultation $[15,16]$. L'espèce la plus isolée au niveau des pieds est Trichophyton rubrum, et à un degré moindre Trichophyton mentagrophytes var. interdigitale. Ce sont actuellement les principaux agents des onychomycoses et des espaces interdigitaux plantaires (pied d'athlète). À titre d'information, la fréquence des onychomycoses des pieds dans la population adulte oscillerait selon les populations ciblées, en cabinet médical ou spécialisé, entre $15 \%$ et $20 \%$. Parmi les facteurs individuels favorisants, outre les troubles trophiques des membres inférieurs, il faut souligner l'excès de transpiration que favorise le port de chaussures fermées et mal aérées et la pratique sportive (natation, judo, marathon, etc.).

On peut donc schématiser ainsi le spectre clinique des dermatophytes à l'échelon mondial, au Sud et dans la ceinture de pauvreté du monde: ce sont les teignes qui prédominent avec avant tout des espèces anthropophiles, tandis qu'au Nord ou chez les populations économiquement plus développées ce sont essentiellement les mycoses du pied et quelques dermatophytoses cutanées dues à des espèces zoophiles ou géophiles.

\section{Origine de la contamination et espèces incriminées}

Il est habituel et classique de classer les dermatophytes selon leur habitat originel (Fig. 1).

\section{Dermatophytes anthropophiles}

La répartition est cosmopolite et la contamination pour ces espèces est toujours interhumaine.

\section{Teignes}

La contamination se fait soit par contact direct ou par l'intermédiaire d'objets comme les taies d'oreillers, les bonnets ou casquettes et des objets de coiffure (peignes, brosses à cheveux, tondeuses, instruments de nattage). En France métropolitaine, les souches anthropophiles représentent près de $90 \%$ des cas de teignes. $T$. soudanense et $M$. audouinii var. langeronii sont les principales espèces, sachant que plus de $70 \%$ des patients touchés sont originaires d'Afrique subsahélienne où ces teignes sont endémiques. T. tonsurans, espèce cosmopolite prédominant sur le continent américain, voit sa fréquence augmenter en France. Dans une étude bien documentée [17], une poupée mascotte de la classe a été à l'origine d'une petite épidémie. La fréquence de $T$. tonsurans passerait de 1,4\% des isolats en 1997 à $7,1 \%$ en 2000 [18], mais une autre étude rétrospective sur 5 ans réalisée en 2006 montre en revanche une certaine stabilité, moins de $3 \%$ des souches isolées [19]. Certaines espèces ont une répartition géographique restreinte: Trichophyton violaceum prédomine en Afrique du Nord, 
T. soudanense en Afrique subsaharienne, M. audouinii var. langeronii en Afrique de l'Ouest et centrale, M. ferrugineum en Asie.

Concernant les épidémies de teigne observées en France, on constate que la contamination intrafamiliale est nettement plus fréquente qu'en milieu scolaire. L'éviction scolaire ne semble aujourd'hui plus justifiée en raison du risque limité de contamination et des contraintes que cela impose aux familles concernées [6]. Elle peut être levée lorsque les enfants concernés sont dépistés et que le traitement débuté est bien suivi. La législation évolue à ce sujet avec plus de souplesse ${ }^{[20]}$.

\section{Mycoses des pieds (pied d'athlète)}

La contamination se fait à partir de supports inertes (carrelage, tapis, tatamis) contenant en surface des débris de kératines humaines virulentes (fragments d'ongles, squames parasitées) issus des sportifs contaminés. À ce propos, il convient de souligner les sites de fréquentation humaine "à risque dermatophytique " collectifs : sols des piscines, douches et vestiaires de salles de sport, et familiaux : tapis de bains, serviettes [21].

L'infection aux pieds débute le plus souvent par un intertrigo méconnu ou négligé, puis le champignon pénètre sous l'ongle et va se développer dans la couche ventrale formant une lésion d'aspect jaunâtre qui va s'étaler en longeant un des sillons latéro-unguéaux vers la lunule (zone qui correspond à la matrice de l'ongle). Progressivement, tout l'ongle peut être envahi. On n'observe pas de périonyxis contrairement aux infections à Candida ou à Fusarium. Les malpositions des orteils favorisent l'infection des ongles des pieds à partir d'un intertrigo mycosique. L'immunodépression est un facteur favorisant important, dans ce cas la prolifération du dermatophyte est beaucoup plus rapide, elle débute par la lunule et aboutit à la destruction de l'ongle en quelques semaines. Il y a aussi des facteurs génétiques, mal connus, de prédisposition, par exemple le syndrome " une main deux pieds " qui correspond à une localisation simultanée à ces niveaux, où $T$. rubrum est souvent impliqué. Pour les intertrigos des grands plis la contamination se fait par contact direct interhumain ou par le biais de vêtement ou de linge de toilette ; une autocontamination à partir d'une autre localisation dermatophytique (par exemple un intertrigo des pieds) est aussi possible.

On observe aussi une atteinte manuelle secondaire après une localisation plantaire chez les sujets qui fréquemment enlèvent de leur pied des fragments de corne cutanée riches en kératine virulente.

\section{Dermatophytoses de la peau glabre}

On observe des localisations cutanées des agents des teignes anthropophiles, il s'agit le plus souvent d'une localisation secondaire. Une entité clinique, le tokélau (dû à Trichophyton concentricum), donne des épidermophyties très extensives et fortement contagieuses [22]. Il convient de souligner également la contagiosité désormais universelle de T. tonsurans dans sa localisation cutanée (Tinea gladiatorum) au cours de la pratique de sports de combats: judo, lutte, pratique de sumo et karaté [23-26].

\section{Dermatophytes zoophiles}

La contamination implique de la même manière un contact direct avec le pelage animal comme le museau des chats et des chiens. Dans ces cas les lésions chez l'homme se trouvent dans des zones de contact fréquent (visage des enfants qui embrassent leur animal familier, bras des adultes). La contamination peut être aussi indirecte par les poils virulents de l'animal laissés sur un coussin pour M. canis (par exemple) ou dans une étable à bovidés (contact ou frottement sur une porte, une chaîne, un harnais) pour T. verrucosum [27]. Les animaux contaminateurs n'ont pas toujours des lésions cliniquement visibles, ce qui les rend épidémiologiquement dangereux.

Le chat (particulièrement le chaton), et à un degré moindre le chien, sont les animaux familiers les plus souvent incriminés avec l'espèce $M$. canis. Dans les milieux de rentes ou d'élevage d'ovins ou de bovins, c'est T. verrucosum qui est le plus incriminé. Chez les chevaux on retrouve préférentiellement des lésions à Trichophyton equinum, à l'origine de dermatophytoses cutanées chez les sujets qui pratiquent un sport équestre. Chez les petits mammifères (cobaye, hamster, souris, lapin) on isole volontiers T. mentagrophytes, et avec le hérisson T. erinacei, la contamination directe chez l'homme est donc plus limitée.

\section{Dermatophytes géophiles}

Ce sont pour la plupart des espèces saprophytes, qui vivent aux dépens de la kératine "morte", issue du sol (fragments de poils, plumes, sabots, carapace d'insecte), volontiers cosmopolites (Trichophyton ajelloi, Trichophyton terrestre, Microsporum cookei). Ces espèces ne sont, en pratique, quasiment jamais impliquées dans des lésions humaines et animales. Il convient donc d'être prudent lors de l'interprétation d'un examen mycologique, lorsque ces espèces sont isolées à partir de lésions suspectes. Seuls Microsporum gypseum, et T. mentagrophytes (à la fois géophile et zoophile) peuvent être considérés comme d'authentiques pathogènes lorsque le contexte clinique s'y prête. Pour ces derniers, la contamination est habituellement accidentelle. Elle nécessite pour que le dermatophyte s'implante sur son hôte un traumatisme direct avec souillure tellurique, d'où la rareté des cas humains. Mais le contact tellurique n'est pas toujours constant, ces dermatophytes géophiles peuvent aussi être véhiculés par un animal transporteur (chien de chasse, souillé de terre par exemple) puis ils vont pouvoir contaminer secondairement leur maître.

Habituellement une dermatophytie causée par une espèce zoophile ou tellurique n'est pas contagieuse d'homme à homme, les lésions sont le plus souvent inflammatoires, et parfois aussi suppurées. Ce sont des espèces non adaptées à la kératine humaine. Ainsi un enfant porteur d'une teigne à $M$. canis aussi étendue soit-elle ne risque pas, a priori, de contaminer son entourage immédiat. Il existe cependant des exceptions, surtout chez les nouveau-nés ou le jeune enfant, ces derniers ont pu être contaminés directement par leurs parents porteurs d'une lésion liée à une espèce zoophile qu'ils avaient eux-mêmes contractée auprès de l'animal porteur, peu ou pas symptomatique (M. canis, Trichophyton verrucosum) [28, 29].

\section{Aspects cliniques des dermatophytoses et principaux diagnostics différentiels}

Les dermatophytes sont à l'origine de lésions superficielles, appelées dermatophytoses, limitées habituellement au niveau de la peau (épiderme) et des phanères (cheveux, poils, ongles).

Selon la localisation et le terrain on peut individualiser plusieurs atteintes chez l'homme.

\section{Teignes du cuir chevelu}

Elles correspondent à l'envahissement du cheveu par un dermatophyte provoquant une cassure totale du cheveu (teigne tondante), parfois dans les teignes zoophiles et telluriques on observe une réaction inflammatoire associée, parfois suppurée, et dans les teignes faviques un décollement du cheveu par la base, entraînant une alopécie définitive.

\section{Teignes tondantes}

Elles touchent principalement l'enfant d'âge scolaire, entre 4 et 10 ans, surtout les garçons chez qui la guérison à la puberté est la règle. Chez les femmes à l'âge adulte on peut retrouver des lésions identiques. Il existe aussi de nombreux «porteurs sains ", notamment chez les femmes adultes, peu ou pas symptomatiques, assurant la dissémination de l'infection dans l'environnement familial.

On distingue classiquement deux formes cliniques.

Teignes tondantes sèches à grandes plaques

Elles sont dues aux dermatophytes appartenant à des Microsporum (d'où l'appellation : teignes microsporiques). Les plaques 
d'alopécie sont peu ou pas inflammatoires, de 1 à $3 \mathrm{~cm}$ de diamètre, les cheveux sont cassés à quelques millimètres du cuir chevelu, les plaques alopéciques ont un aspect grisâtre.

Jusqu'au début $\mathrm{du} \mathrm{xx}^{\mathrm{e}}$ siècle $M$. audouinii était la principale espèce incriminée en Europe, puis avec le développement du niveau de vie, les cas autochtones ont disparu. Ce dermatophyte se maintient cependant en zone urbanisée où vit une population d'origine africaine. Des épidémies à $M$. audouinii var. langeronii dont le point de départ est un cas importé sont régulièrement décrites ${ }^{[30,31]}$.

M. canis, dans les années 1960-1970 s'est imposé, compte tenu de l'engouement pour nos animaux familiers, le chien mais surtout le chat, et plus anecdotiquement les lapins, les cobayes, les hamsters. M. canis reste actuellement le principal agent de teigne microsporique en France métropolitaine.

Les plaques d'alopécie de ces teignes à "grandes plaques » sont habituellement fluorescentes en lumière de Wood. Ces teignes peuvent être associées à des localisations cutanées (dermatophytoses circinées).

Les teignes du cuir chevelu régressent spontanément à la puberté, excepté chez les femmes, surtout originaires d'Afrique noire.

Teignes tondantes à petites plaques d'alopécie, ou teignes trichophytiques

Elles sont, en revanche, uniquement dues à des Trichophyton anthropophiles ( $T$. violaceum, $T$. soudanense, $T$. tonsurans, etc.).

Les cheveux cassés courts au ras du cuir chevelu sont englobés dans des squames ou croûtes. Les zones d'alopécie au départ de très petite taille rendent le diagnostic difficile. Plus tard, les plaques d'alopécie fusionnent donnant de plus grandes plaques mais non arrondies. Cependant, des cheveux parfois longs restent présents sur ces plaques. Des zones squameuses et prurigineuses sont souvent bien visibles au niveau des raies issues de coiffures traditionnelles, notamment chez les petites filles africaines. Dans les teignes trichophytiques, les cheveux parasités ne sont pas fluorescents en lumière de Wood, c'est un critère distinctif important.

Ces teignes, observées en France, sont pratiquement toujours importées. Les teignes à $T$. soudanense se rencontrent volontiers chez les enfants adoptés issus d'Afrique subsahélienne (Éthiopie, Mali), celles à $T$. tonsurans proviennent surtout du continent américain, notamment des Caraïbes (Haïti), enfin celles à T. violaceum sont issues d'enfants d'immigrants maghrébins, de retour de leur pays d'origine. Les teignes à T. rubrum restent rares ${ }^{[29]}$ et le plus souvent associées à des localisations cutanées ou des ongles [32].

\section{Teignes suppurées (kérion, sycosis)}

Les teignes suppurées sont dues surtout aux dermatophytes zoophiles (surtout T. mentagrophytes, T. verrucosum) ou telluriques (Microsporum gypseum), rarement anthropophiles ( $T$. violaceum). Chez l'homme, le cuir chevelu est très rarement atteint, à l'inverse de l'enfant chez qui les kérions ne sont pas rares en région d'élevage, en revanche les lésions au niveau de la barbe appelées sycosis et de la moustache sont habituelles chez l'adulte.

Chez la femme les kérions du cuir chevelu ne sont pas exceptionnels.

Les teignes suppurées se présentent comme des placards ronds, très inflammatoires, limités puis confluents de plusieurs centimètres de diamètre et volontiers surélevés. Très rapidement, ces placards se recouvrent de pustules laissant couler un pus jaunâtre. Les cheveux ou les poils s'éliminent spontanément. La présence d'adénopathies satellites traduit une surinfection bactérienne. Habituellement, il n'y a pas de fièvre.

L'évolution est spontanément régressive en quelques semaines ou quelques mois. Les cheveux repoussent habituellement sans séquelles sauf si une surinfection bactérienne s'est ajoutée, auquel cas une antibiothérapie est nécessaire en plus du traitement antifongique.

\section{Teigne favique ou favus}

Cette affection, jadis observée dans les campagnes reculées, a pratiquement disparu en France du fait de l'augmentation du niveau d'hygiène. De rares cas sont observés chez des sujets originaires d'Afrique (notamment en Afrique du Nord), mais la prévalence dans ces régions diminue fortement ${ }^{[33-35]}$ avec le développement du niveau de vie.

La teigne favique est due à Trichophyton schoenleinii. Les cheveux ne cassent pas, ils se détachent car ils sont atteints par la base. L'accumulation du mycélium va entraîner la formation d'une petite croûte jaunâtre, friable, centrée par un cheveu : le " godet favique». Les cheveux décollés vont tomber, donnant une alopécie définitive. Les godets peuvent ensuite fusionner donnant des éléments de plus grande taille : les croûtes faviques.

Au départ l'infection, très discrète, est la plupart du temps méconnue. Elle ne devient cliniquement évidente qu'après des années d'évolution, où des plaques d'alopécie se sont formées, une odeur de souris est classiquement soulignée.

Dans le favus, contrairement aux autres teignes, il n'y a pas de guérison spontanée à la puberté, l'évolution se poursuit tant qu'il existe des cheveux. L'alopécie cicatricielle qui en résulte est définitive.

La recherche d'une fluorescence en lumière de Wood aide au diagnostic, en effet dans le favus les cheveux malades sont fluorescents sur toute leur longueur. Le prélèvement peut ainsi être réalisé de façon plus efficace sous lumière de Wood. À l'atteinte du cuir chevelu peuvent s'associer des godets cutanés et des onyxis des mains. La teigne favique est contagieuse à l'origine de cas intrafamiliaux.

\section{Diagnostic différentiel des teignes du cuir chevelu}

De nombreuses affections dermatologiques simulent une teigne, imposant le prélèvement mycologique :

- la pelade, mais absence d'anomalie du cuir chevelu, celui-ci reste lisse, non squameux ;

- la fausse teigne amiantacée : on y observe des squames blanc jaunâtre englobant les cheveux par paquets ;

- les alopécies cicatricielles ;

- les pseudopelades (lupus érythémateux disséminé, lichen plan, sarcoïdose, sclérodermie localisée, etc.) ;

- les infections bactériennes lorsqu'il s'agit d'un kérion.

\section{Atteintes de la peau glabre}

\section{Dermatophytoses circinées}

Ce sont des lésions cutanées de la peau glabre, qui surviennent en général 1 à 3 semaines après le contact infectant, la présence d'une microlésion suffirait aux spores virulentes pour germer dans l'épiderme. La lésion élémentaire est arrondie ("roue de sainte-Catherine») dont la zone active (bourrelet inflammatoire) est en périphérie, là où le champignon se développe de façon centrifuge. À ce niveau on peut distinguer à la loupe des petites vésicules, d'où le terme anciennement utilisé et aujourd'hui obsolète $d^{\prime}$ " herpès circiné ». Le centre de la lésion, en revanche, semble en voie de guérison. Le prurit est inconstant.

Tous les dermatophytes peuvent être à l'origine de dermatophytoses de la peau glabre. T. rubrum et $M$. canis sont cependant les principaux rencontrés en France métropolitaine.

Les lésions peuvent se situer sur toutes les parties du corps mais principalement sur les parties découvertes (face, cou, main, jambe), là où le contact infectant se produit. Elles peuvent être isolées ou multiples. Lorsque plusieurs plaques confluent, le contour de la lésion devient polycyclique dessinant une carte de géographie. Selon le dermatophyte en cause, on peut observer des aspects différents, ainsi T. rubrum donne souvent de grandes plaques pustuleuses extensives, tandis qu'avec les espèces zoophiles comme T. mentagrophytes, Microsporum persicolor, $T$. erinacei et $T$. verucosum les lésions sont peu extensives et volontiers surélevées et inflammatoires. 
Le diagnostic différentiel se pose avec de nombreuses affections cutanées pouvant simuler ces dermatophyties : eczéma nummulaire, eczématides, pityriasis rosé de Gibert, d'où la nécessité de recourir au prélèvement mycologique.

\section{Tokélau ou « Tinea imbricata »}

Cette affection qui touche exclusivement la peau se rencontre essentiellement dans certaines îles du Pacifique (Mélanésie, Polynésie), plus rarement en Asie du Sud-Est, au Sri Lanka et en Amérique du Sud. Elle est due à une seule espèce : T. concentricum. Les lésions débutent dans l'enfance. L'aspect clinique est pathognomonique, les lésions squameuses superficielles, volontiers confluentes, se présentent comme des cercles concentriques où en périphérie se détachent facilement de fines squames blanchâtres. Les lésions sont très extensives, tout le revêtement cutané peut être touché. Les rechutes sont fréquentes.

\section{Syndrome dermatophytique chronique}

Il survient surtout chez des sujets ayant un déficit immunologique inné ou acquis ou soumis à un traitement prolongé par corticoïdes ou autres immunosuppresseurs. T. rubrum est pratiquement toujours en cause. Les lésions volontiers polymorphes sont étendues et plurifocales au niveau des pieds, des plantes, des mains (paumes).

\section{Atteintes des plis ou intertrigos}

Les intertrigos correspondent à l'atteinte d'un pli par un dermatophyte pratiquement toujours anthropophile.

On distingue les intertrigos des petits plis, plantaires, palmaires parfois, des intertrigos des grands plis (inguinopérinéaux, interfessiers ou des creux axillaires) [36]. Ils sont dus le plus souvent à des espèces anthropophiles, T. rubrum, T. mentagrophytes var. interdigitale et Epidermophyton floccosum.

\section{Intertrigo des petits plis}

Ce sont les localisations les plus fréquentes des dermatophytes dans les pays développés où la pratique sportive est très répandue.

L'intertrigo inter-digito-plantaire débute généralement dans le dernier espace interorteils. Les lésions se présentent d'abord par une fissuration et macération de la peau, puis apparaît une plaque fibreuse blanchâtre du fond du pli, accompagnée d'une desquamation. La peau devient blanchâtre, s'épaissit, formant à la longue une lésion blanche nacrée, épaisse.

D’autres aspects (vésiculeux, vésiculobulleux ou hyperkératosiques) sont aussi observés. Des signes fonctionnels (sensation de prurit ou de brûlures) sont souvent associés entraînant le sujet à consulter.

L'extension peut se faire à la plante du pied (aspect en «mocassin »), sur les bords et le dos du pied et aux ongles.

Après des années d'évolution, il se forme une véritable pachydermie de la plante du pied. L'intertrigo des pieds à dermatophytes surinfectés peut se compliquer d'érysipèle.

Aux mains, l'intertrigo dermatophytique (Tinea manuum) est moins fréquent, il est dû surtout à T. rubrum.

À ce niveau, l'intertrigo est habituellement sec, non érythémateux, peu prurigineux. Il peut s'étendre et provoquer un épaississement cutané de la paume de la main lui donnant une consistance cartonnée. Les ongles de la main, comme ceux du pied, sont secondairement atteints.

\section{Intertrigo des grands plis}

Le plus fréquent, surtout rencontré chez l'adulte, est localisé aux plis inguinaux (ancien eczéma marginé de Hébra). La lésion, centrée par le pli, bilatérale et prurigineuse, se présente comme une macule rosée, dont la surface est finement squameuse avec une bordure périphérique nette, festonnée, érythématovésiculeuse avec parfois des petites lésions satellites, identiques, isolées à proximité. T. rubrum et plus rarement E. floccosum sont en cause.

Aux creux axillaires ou dans le pli interfessier, les lésions sont plus rares. Elles sont également centrées par le pli. Au pli axillaire, l'atteinte bilatérale en "feuillet de livre » avec une bordure périphérique nette est caractéristique. L'espèce habituellement en cause est E. floccosum.

\section{Diagnostic différentiel des intertrigos dermatophytiques}

Le diagnostic différentiel se pose aux pieds, et plus fréquemment aux mains, avec les intertrigos d'origine candidosique. La peau est alors macérée, humide, blanchâtre et se décolle, formant une fente au centre du pli, parfois douloureuse, elle est non prurigineuse. Aux pieds, le premier espace interorteils est atteint de façon préférentielle ; aux mains, il s'agit du troisième espace.

Aux plis inguinaux ou axillaires, l'érythrasma est également une affection fréquente. Il provoque des lésions non prurigineuses, non douloureuses, centrées aussi sur le pli, formant un placard de couleur rosée à bistre, de teinte homogène. Une fine desquamation est fréquente. Cette affection est provoquée par des corynébactéries, Corynebacterium minutissimum. Il existe une fluorescence rouge corail en lumière de Wood du fait de la sécrétion de porphyrines.

Des moisissures peuvent être aussi à l'origine d'intertrigos et d'onyxis associés semblables à ceux provoqués par les dermatophytes, ils sont appelés «pseudodermatophytes". Ce sont: Onychocola canadensis qui affectionne les pieds dans les pays du Nord, Neoscytalidium dimidiatum et Neoscytalidium hyalinum au contraire dans les régions tropicales.

D'autres diagnostics non mycosiques ou non bactériens sont à envisager, comme le psoriasis.

\section{Atteintes des paumes des mains}

Les dermatophytes provoquent une dermatose subaiguë ou chronique de la paume d'une main, le plus souvent due à T. rubrum. Il s'agit souvent d'un patient du sexe masculin, porteur d'un intertrigo des pieds depuis de nombreuses années. L'infection débute à bas bruit par la formation de vésicules peu ou pas prurigineuses qui sèchent rapidement, suivies par d'autres entraînant à la fois une desquamation et un épaississement de la peau sur une base érythémateuse. Le pourtour des lésions est peu marqué, on ne distingue pas de bourrelet périphérique comme dans les autres dermatophytoses. Progressivement, toute la paume est atteinte, les espaces interdigitaux, puis survient un onyxis des mains. La paume ainsi que la face palmaire des doigts prend à un stade avancé un aspect farineux, les plis palmaires et digitaux sont accentués du fait de l'hyperkératose encore plus importante à ces endroits.

Ces lésions n'ont aucune tendance à la régression spontanée, leur aspect peu évocateur de dermatophytose entraîne fréquemment des erreurs de diagnostic (eczéma, "gale du ciment»).

\section{Atteintes des ongles ou onyxis à dermatophytes ${ }^{[37,38]}$}

Il s'agit d'une pénétration de la kératine de l'ongle par un dermatophyte. Cette infection est habituellement secondaire à une dermatophytose de proximité, notamment les intertrigos.

Cette pathologie est un motif fréquent de consultation en dermatologie. Les onychomycoses représentent les formes cliniques les plus fréquentes des dermatophytes. Cosmopolites, la fréquence de ces onychomycoses varie chez l'homme en fonction de nombreux facteurs, climatiques, socioprofessionnels ou socio-économiques, notamment liés au mode de vie. Si la prévalence est faible chez l'enfant, elle augmente avec l'âge pour atteindre $30 \%$, voire $48 \%$ et plus chez les patients âgés de plus de 70 ans. Les dermatophytes eux-mêmes représentent environ les trois quarts des étiologies fongiques [16].

Les onyxis à dermatophytes des pieds, en particulier du gros orteil, sont les plus fréquents (plus de $90 \%$ des onychomycoses). Ils sont dus à des espèces anthropophiles responsables aussi d'intertrigo inter-digito-plantaire. Le dermatophyte le plus impliqué est T. rubrum, suivi par T. mentagrophytes var. interdigitale et plus rarement par E. floccosum.

Les atteintes des ongles des mains sont le plus souvent dues à des Candida, les dermatophytes arrivent en seconde position, 


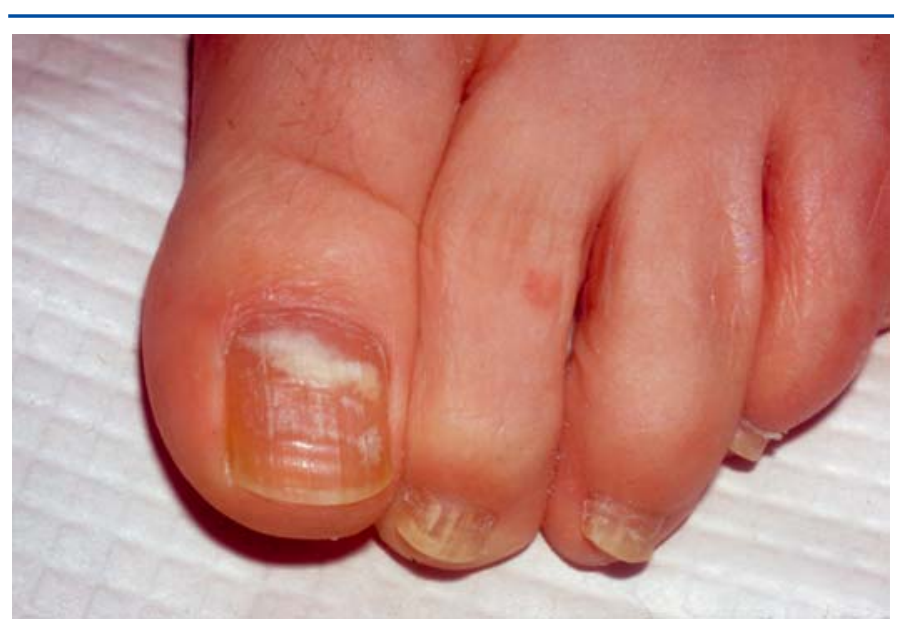

Figure 2. Onychomycose proximale due à Trichophyton mentagrophytes var. interdigitale (collection du Dr Guy Badillet).

T. rubrum essentiellement. On peut également retrouver dans un ongle pathologique les agents des teignes anthropophiles (T. violaceum, T. soudanense, voire plus exceptionnellement T. schoenleinii). Une espèce zoophile, $M$. canis, peut parfois être isolée chez des patients immunodéprimés. Ces onychomycoses à dermatophytes des mains proviennent le plus souvent d'une autocontamination par un intertrigo des pieds ou plus rarement une teigne.

On décrit classiquement quatre formes cliniques d'onyxis à dermatophytes ${ }^{[3,38]}$.

\section{Onychomycose sous-unguéale distale (ou latérodistale)}

C'est le type le plus souvent observé.

Le dermatophyte prolifère dans le lit de l'ongle à partir du bord distolatéral en direction de la matrice. Il provoque une hyperkératose friable sous-unguéale et un détachement de la tablette unguéale. L'aspect clinique est celui d'une tache jaune à brune, plus ou moins foncée. Les modifications de couleur peuvent s'expliquer par la surinfection par des moisissures, ou par la sécrétion d'un pigment mélanique par le dermatophyte (T. rubrum ou T. mentagrophytes var. interdigitale). L'atteinte de l'ongle s'étend progressivement à la zone matricielle proximale.

\section{Onychomycose sous-unguéale proximale}

Cette forme clinique est plus rare. Contrairement à ce que l'on observe habituellement, l'ongle n'est pas contaminé par son bord libre mais par son extrémité proximale au niveau de la lunule (Fig. 2). L'infection se traduit d'abord par une lésion blanchâtre (ou leuconychie) à la base de l'ongle, (qui correspond à la kératine fragilisée), cette lésion s'étend, puis la tablette unguéale se perfore, éliminant de la poudre constituée de kératine et de mycélium, cela aboutit à la destruction de l'ongle. Il peut aussi exister une variante "bipolaire » avec atteinte superficielle et profonde. Ces aspects sont plus volontiers observés chez des patients immunodéprimés (greffés, traitement par corticoïdes au long cours, patients atteints de sida).

\section{Leuconychies}

Il s'agit de lésions unguéales d'origine fongique se présentant comme des taches blanches, de taille variable, correspondant à une atteinte de la tablette unguéale superficielle (Fig. 3). L'atteinte peut se limiter à la tablette supérieure de l'ongle (leuconychies superficielles), dans ce cas, le prélèvement et le traitement sont faciles, il se fait prioritairement en limant les plaques où la kératine est friable. Le dermatophyte isolé est surtout T. mentagrophytes var. interdigitale, on peut aussi trouver à ce niveau des moisissures. L'ongle peut aussi être atteint dans toute son épaisseur (leuconychies profondes) chez l'immunodéprimé, dans ce cas, seul un traitement médicamenteux prolongé assure la guérison.

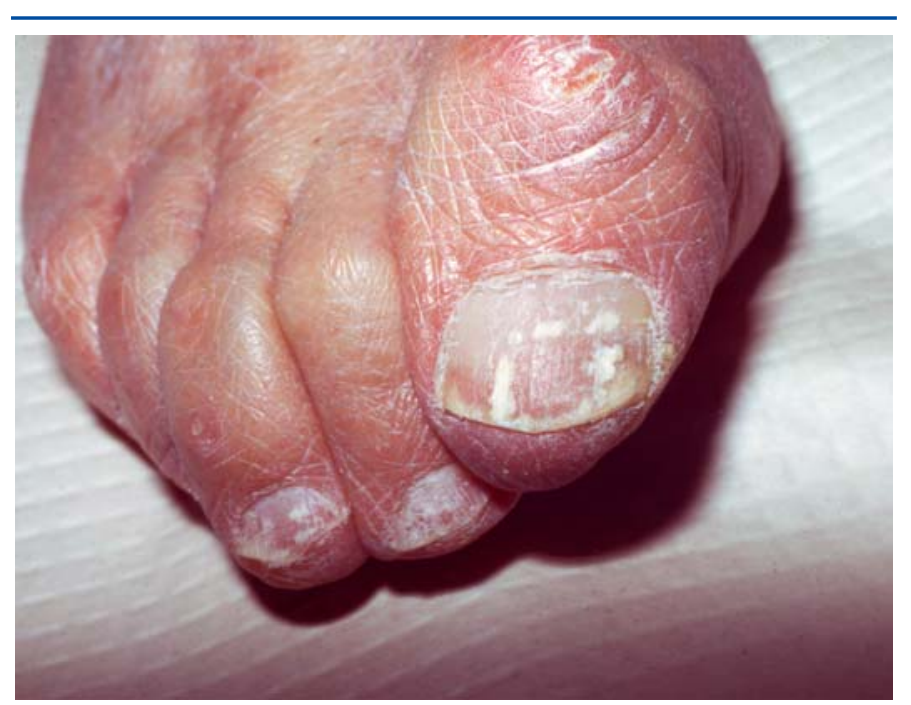

Figure 3. Leuconychies superficielles dues à Trichophyton mentagrophytes var. interdigitale (collection du Dr Guy Badillet).

Une nouvelle forme d'envahissement de l'ongle a été décrite récemment ${ }^{[39]}$, le champignon pénètre directement dans la kératine distale formant des taches blanc laiteux sans hyperkératose sous-unguéale, ni onycholyse. Il s'agit de l'endonyx décrit avec $T$. soudanense mais aussi retrouvé avec $T$. violaceum, tous les deux agents de teignes du cuir chevelu.

\section{Onycho-myco-dystrophie totale}

Cet aspect correspond à une destruction totale de l'ongle par le dermatophyte.

On distingue l'onycho-myco-dystrophie totale "primitive», rare avec les dermatophytes en dehors de la maladie dermatophytique, de l'onycho-myco-dystrophie dite «secondaire» qui traduit l'évolution inexorable de la progression du champignon dans l'ongle sans traitement.

\section{Diagnostic différentiel des onychomycoses à dermatophytes}

Les onychomycoses, dont les onyxis à dermatophytes, représentent les principales étiologies participant à plus de $40 \%$ de la pathologie unguéale. En pratique, malgré l'aspect de mycose, rien ou presque ne permet cliniquement de distinguer une hyperkératose sous-unguéale distale d'origine mycosique d'un psoriasis de l'ongle ou d'un syndrome de Fiessinger-LeroyReiter, par exemple. D'autres onychopathies (maladie de Darier, pelade, lichen, eczéma de contact, etc.) peuvent aussi donner des hyperkératoses et simuler une mycose. Des modifications de couleur de l'ongle, classiques avec certaines espèces de champignons, se rencontrent lors d'un hématome sous-unguéal, ou dans les suites d'un traumatisme ou de frictions répétées; parfois, il faut craindre un mélanome. Le diagnostic clinique est difficile surtout lorsque l'atteinte de l'ongle est isolée. Un prélèvement mycologique doit toujours être fait avant la mise en route du traitement antifongique, car celui-ci est de longue durée et donné per os. Parmi les atteintes fongiques autres que celles dues aux dermatophytes de l'ongle il faut distinguer :

- les onyxis à Candida, surtout fréquents au niveau des ongles des mains. L'infection débute habituellement par un périonyxis (paronychie). Elle commence sur les bords latéraux de l'ongle, parfois sur le bord libre surtout lorsqu'il s'agit de levures autres que Candida albicans (Candida parapsilosis);

- les onychomycoses à moisissures sont plus rares que celles dues aux dermatophytes ou aux levures, elles représentent environ $3 \%$ à $6 \%$ des étiologies fongiques. Des moisissures appelées "pseudodermatophytes ", car à l'origine de lésions simulant une dermatophytose comme des Neoscytalidium (rencontrés dans les régions tropicales) et Onychocola canadensis (au contraire isolé dans les pays tempérés ou froids, au Nord), sont responsables d'onychomycoses sous-unguéales 


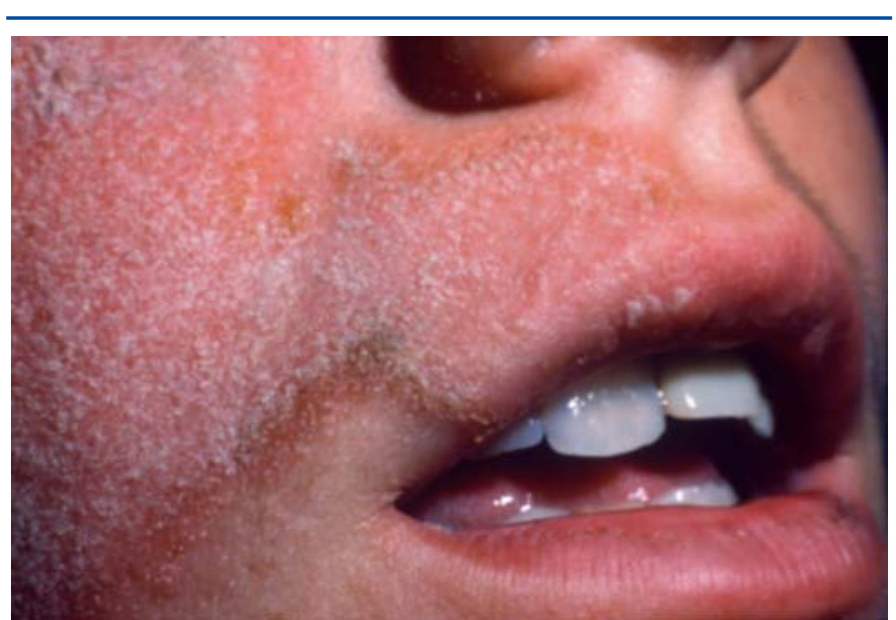

Figure 4. Dermatophytoses de la peau et des lèvres dues à Trichophyton verrucosum (collection du Dr Guy Badillet).

distales pouvant être associées à un intertrigo. D'autres moisissures cosmopolites comme Scopulariopsis brevicaulis, certains Aspergillus (Aspergillus versicolor), Fusarium (Fusarium oxysporum), Acremonium (Acremonium strictum), Paecilomyces (Paecilomyces lilacinus), se comportent parfois comme d'authentiques kératinophiles parasites de l'ongle, dans ces cas l'intertrigo est absent. Les invasions de l'ongle par les moisissures surviennent habituellement après un traumatisme de l'ongle, voire sur un ongle pathologique. Leur implantation est favorisée par des altérations de la kératine et des troubles trophiques et vasculaires. Mais ces champignons peuvent également surinfecter une véritable onychopathie dermatophytique.

Les moisissures sont à l'origine d'onychomycoses d'évolution très lente aboutissant, sans traitement, à une onycho-mycodystrophie totale.

\section{Dermatophytoses plus rares}

\section{Tinea incognita}

L'utilisation de dermocorticoïdes sur des lésions cutanées occasionnées par des dermatophytes entraîne des modifications donnant des aspects cliniques trompeurs à type de papulopustules pas toujours bien limitées qui égarent le diagnostic.

\section{Dermatophyties des muqueuses et des demi-muqueuses}

Les atteintes génitales sont rares; on décrit des atteintes des grandes lèvres chez la femme et du pénis chez l'homme simulant une balanite candidosique. T. rubrum a été isolé de lésions circinées du gland chez des circoncis ${ }^{[40]}$. Les atteintes des plis inguinocruraux peuvent secondairement atteindre la demimuqueuse vulvaire. La zone anale est en revanche plus rarement incriminée.

Les lèvres de la cavité buccale sont plus touchées suite à un contact affectueux avec un animal familier (chat, chien, lapin). Chez l'enfant on observe des atteintes de la face, du visage (joue, nez, menton), avec extension aux lèvres (chéilite) (Fig. 4).

L'application de pommade aux corticoïdes sur ces lésions simulant un eczéma révèle souvent la mycose. $M$. canis, $M$. persicolor et T. mentagrophytes sont les espèces les plus isolées à ces endroits.

\section{Granulome de Majocchi et dermatophytoses disséminées ou profondes ${ }^{[41-50]}$}

Le point de départ d'un granulome de Majocchi est constitué de follicules pilaires qui, contaminés par le dermatophyte, se rompent dans le derme. Les principaux facteurs favorisants sont la corticothérapie locale et un terrain immunodéprimé. Sur le plan clinique les lésions qui siègent volontiers au niveau des membres ressemblent à des papules ou nodules enchâssés dans le derme, de couleur rosée. Histologiquement, dans sa description princeps il s'agit d'un granulome centré par un fragment de poil parasité.

D'autres atteintes profondes, sans atteintes folliculaires, sont aussi rapportées, prenant l'aspect de nodules ou de placards infiltrant le derme d'allure papuleuse, parfois croûteuse, situés sur le visage, le cuir chevelu, le tronc, les membres et les plis. Des adénopathies de voisinage peuvent se voir, mais les formes systémiques (avec localisation osseuse, hépatiques, spléniques, pulmonaires, neurologiques) au pronostic très sombre, restent rares. Une revue récente [50] fait état de 70 cas de dermatophytoses disséminées rapportés dans la littérature anglo-saxonne et espagnole depuis 1883. On retrouve dans ces formes disséminées souvent une dermatophytose préexistante et un terrain prédisposé : sujets porteurs du virus de l'immunodéficience humaine (VIH), avec un taux de CD4 effondré, patients transplantés (cœur, rein) sous immunosuppresseurs (tacrolimus, azathioprine, cyclophosphamide, infliximab), corticothérapie, chimiothérapie, etc. Récemment, on a décrit une observation de dermatophytose cutanée disséminée à T. rubrum chez un patient atteint d'une cirrhose hépatique et porteur d'une hémochromatose héréditaire [50].

\section{Maladie dermatophytique ou maladie de Hadida et Schousboë $[51-55$}

La maladie dermatophytique est une affection très rare, elle a surtout été décrite en Afrique du Nord. L'Algérie est le pays le plus touché. Des cas sporadiques ont été cependant observés en Europe centrale, au Japon et chez des aborigènes en Australie. Elle survient sur un terrain familial particulier : contexte d'endogamie avec un taux de consanguinité important et déficit sélectif de l'immunité cellulaire vis-à-vis des Trichophytons. Récemment une étude aurait montré que les lymphocytes CD8 de type TC2 suppresseurs sécrétant de l'interleukine 4 (IL-4) et de l'IL-5 seraient à l'origine du déficit immunitaire. Le champignon traverse la membrane basale et envahit les tissus profonds. T. violaceum, T. rubrum, T. schoenleinii, T. verrucosum et T. tonsurans sont les espèces en cause. Les Microsporum ne sont que très rarement incriminés (exclusivement $M$. canis).

La maladie touche surtout le sujet de sexe masculin et se déclare souvent dans l'enfance, elle débute souvent au cuir chevelu par une teigne sèche récidivante très squameuse ou sur la peau comme une lésion érythématosquameuse étendue. Ces lésions cutanées s'étendent progressivement et se transforment en nodules ou gommes pouvant s'ulcérer (atteinte du derme et de l'hypoderme), et se recouvrent de végétations, de verrucosités et de cornes. Secondairement, les ongles sont contaminés à leur tour et se compliquent parfois d'une onychogryphose.

Une généralisation se fait aux ganglions, puis aux os et au cerveau. D'autres localisations peuvent se voir: foie, aponévrose, thymus, etc. Parfois les lésions restent nodulaires, superficielles, mais s'étendent progressivement sur tout le corps. L'évolution de la maladie dermatophytique est désespérément chronique avec des améliorations transitoires avec le traitement systémique, mais les rechutes sont fréquentes et le pronostic reste sombre.

Le diagnostic différentiel se pose avec les mycétomes à dermatophytes et le granulome de Majocchi. L'affection due au VIH peut provoquer des lésions similaires étendues, partiellement invasives, mais réversibles avec l'augmentation des CD4.

\section{Mycétomes à dermatophytes ${ }^{[56]}$}

Les mycétomes à dermatophytes sont des affections très rares dans lesquelles le dermatophyte a aussi franchi la barrière cutanée mais il forme des grains dans le derme. Les auteurs anglo-saxons préfèrent le terme de pseudomycétome car l'agent pathogène, présent sur le cuir chevelu, n'est pas d'origine exogène comme les autres agents de mycétomes.

Ces mycétomes sont dus essentiellement à M. audouinii, mais aussi T. rubrum, M. canis, M. ferrugineum, T. tonsurans, T. soudanense et $T$. schoenleinii.

Ils surviennent habituellement chez des patients sous corticothérapie prolongée qui présentent une teigne du cuir chevelu ou une dermatophytose circinée. 
Les lésions se présentent sous forme de tumeur bourgeonnante ou de nodules hypodermiques érythémateux, douloureux, centrés par un cheveu ou un poil. Ils peuvent s'ulcérer. Une teigne concomitante, proche de la lésion, due à la même espèce, est aussi souvent observée.

Le diagnostic différentiel se pose avec la maladie dermatophytique à son début, une lésion furonculeuse, un lipome, une tumeur évoquant un processus malin.

Le diagnostic repose sur la biopsie cutanée profonde avec examen anatomopathologique, qui montre dans le derme des filaments mycéliens agglomérés en grains, entourés de matériel éosinophile (phénomène de Splendore-Hoëppli), et d'une couche de cellules épithélioïdes et de cellules géantes. Le dermatophyte responsable est isolé après la culture du grain.

\section{Atteintes de nature allergique appelées « dermatophytides »}

Les dermatophytides sont des réactions allergiques à distance du foyer infectieux initial. Elles sont produites par la libération dans le sang de produits allergisants provenant du dermatophyte (T. rubrum ou T. mentagrophytes var. interdigitale, etc.).

Ces dermatophytides se présentent comme des lésions d'allure eczématiforme, de localisation variée (surtout au niveau des mains) appelées aussi «dyshidrose ». Le prélèvement et la recherche mycologique à leur niveau restent stériles.

La guérison de ces dermatophytides est obtenue lorsque l'on traite efficacement le foyer mycosique d'origine.

\section{Diagnostic au laboratoire ${ }^{[57-61]}$}

\section{Introduction, démarche diagnostique (Fig. 5)}

Le diagnostic repose sur l'interrogatoire (de l'accompagnant lorsqu'il s'agit d'un enfant), afin de préciser l'histoire de la lésion, sa date d'apparition, son évolution. Il est nécessaire de rechercher d'autres localisations, de préciser le contexte épidémiologique (traitement ou pathologie sous-jacente, pratique sportive, profession exposée, notion de voyage, de contamination vis-à-vis d'un animal familier, voire de rente ou d'élevage). L'examen avec une lampe de Wood s'impose dans la salle d'examen en cas de suspicion de teigne. Ailleurs, l'utilisation d'un microscope à laser confocal, par transillumination des couches cornées superficielles, permet d'observer les éléments mycéliens au sein même des lésions, mais cet examen, qui nécessite un opérateur entraîné, reste peu utilisé [57].

En pratique, c'est l'étude mycologique (recherche et identification du champignon responsable) qui doit être dans tous les cas réalisée et ceci avant tout traitement antifongique.

Le diagnostic repose sur le prélèvement qui doit être de bonne qualité, le préleveur doit connaître parfaitement la sémiologie clinique des dermatophytes. Le prélèvement doit être suffisamment abondant pour pouvoir réaliser correctement l'examen direct et la culture. L'examen direct des produits prélevés, incontournable, permet de rendre un premier résultat, quasi immédiatement.

L'identification du dermatophyte fait appel à des méthodes conventionnelles [58-61]. L'ensemencement se fait d'emblée sur milieu de Sabouraud, mais il est parfois nécessaire de repiquer les primocultures sur des milieux spéciaux d'identification.

D'autres techniques complémentaires peuvent aider au diagnostic d'espèce, la recherche d'uréase et la recherche des organes perforateurs pour différencier, par exemple, les deux principales espèces isolées au laboratoire, $T$. rubrum et $T$. mentagrophytes var. interdigitale. L'inoculation au cobaye ou le recours à l'anatomopathologie (sauf pour les mycétomes et les formes invasives) sont moins usités. L'identification des espèces par spectrométrie de masse (MALDI-TOF) est prometteuse [62], mais les protocoles sont encore à l'état expérimental. Les techniques immunologiques ne sont plus utilisées au diagnostic. En revanche, l'utilisation de techniques de biologie moléculaire peut suppléer aux limites du diagnostic morphologique.

\section{Prélèvement}

C'est l'étape incontournable du diagnostic mycologique. Il est nécessaire de le réaliser avant tout traitement spécifique. Dans le cas contraire, une fenêtre thérapeutique de 15 jours pour la peau et le cuir chevelu et de 3 mois pour les ongles est exigée.

Pour les teignes du cuir chevelu, un examen en lumière de Wood doit être réalisé dans une pièce où l'obscurité est totale. Une fluorescence verte est observée dans le cas de teignes tondantes microsporiques et dans la teigne favique.

On prélève à l'aide d'une pince à épiler ou d'une curette les cheveux suspects (fluorescents) et les squames du cuir chevelu. En cas de teigne inflammatoire (ou kérion) le préleveur utilise plutôt des écouvillons à frotter sur les zones suintantes, quelques cheveux ou poils peuvent être retirés à la pince à épiler. En cas de favus, on racle le fond des godets pour prélever les cheveux parasités enchâssés dans les croûtes. Sur la peau glabre et au niveau des ongles, le prélèvement se fait à la curette préférentiellement où le champignon est « en activité ", c'est-àdire à la périphérie des lésions à la limite de la peau saine ou de l'ongle sain.

Nous préconisons que le prélèvement soit réalisé dans des laboratoires d'analyse médicale où de plus en plus de biologistes sont formés à la mycologie. Dans le cas contraire, les prélèvements peuvent être réalisés au cabinet de consultation. Quel que soit le préleveur, ce dernier doit être initié à la pratique des prélèvements à visée mycologique. Les conditions de transport ne sont pas aussi rigoureuses que pour la bactériologie, les fragments de squames, d'ongles et de cheveux doivent être transportés dans des flacons à sec. Ils peuvent être conservés à température ambiante plusieurs jours. Le laboratoire-receveur, s'il ne pratique pas le prélèvement doit, outre l'identification du patient, connaître la date de début de la lésion et son siège précis ainsi que les renseignements d'ordre épidémiologique indispensables pour confronter le diagnostic d'espèce au contexte épidémioclinique du patient.

\section{Examen direct}

Il est indispensable et doit être réalisé rapidement afin d'apporter une réponse rapide au clinicien prescripteur. On utilise au laboratoire volontiers des liquides éclaircissants (solution de potasse, chloral-lactophénol, noir chlorazol), ou des fluorochromes (Calcofluor ${ }^{\circledR}$, Blankophor $\left.{ }^{\circledR}\right)^{[63]}$. Pour les teignes du cuir chevelu, l'étude du parasitisme pilaire est très prédictive de l'espèce en cause, ce dernier donne des renseignements épidémiologiques intéressants. Par exemple, les teignes endothrix sont toutes dues à des Trichophyton anthropophiles (Fig. 6), le clinicien peut proposer un traitement immédiat et déclencher une enquête familiale.

Les teignes endoectothrix sont de type microsporique ou microïde.

Enfin, le type favique signe la teigne à $T$. schoenleinii.

Dans les autres prélèvements (squames et fragments d'ongles parasités) l'examen direct n'objective que des «filaments mycéliens septés » (arthrosporés).

Ces filaments confirment l'existence d'une mycose, vraisemblablement d'origine dermatophytique, tout en sachant que des «moisissures » d'intérêt médical, notamment dans l'ongle, peuvent aussi être incriminées.

En cas d'examen direct négatif, il convient d'attendre le résultat des cultures pour confirmer le diagnostic d'espèce. Le traitement peut être ajusté ensuite après l'identification du champignon responsable.

\section{Examen anatomopathologique}

Il est peu usité dans la majorité des cas du fait du caractère habituellement superficiel des lésions. Toutefois, dans les formes atypiques, notamment chez les patients $\mathrm{VIH}$, dans les formes profondes ou invasives, le granulome de Majocchi et l'exceptionnelle maladie dermatophytique, l'anatomopathologie s'avère indispensable.

Dans les onychomycoses, l'histomycologie unguéale est aussi contributive au diagnostic, l'examen direct mycologique peut se 


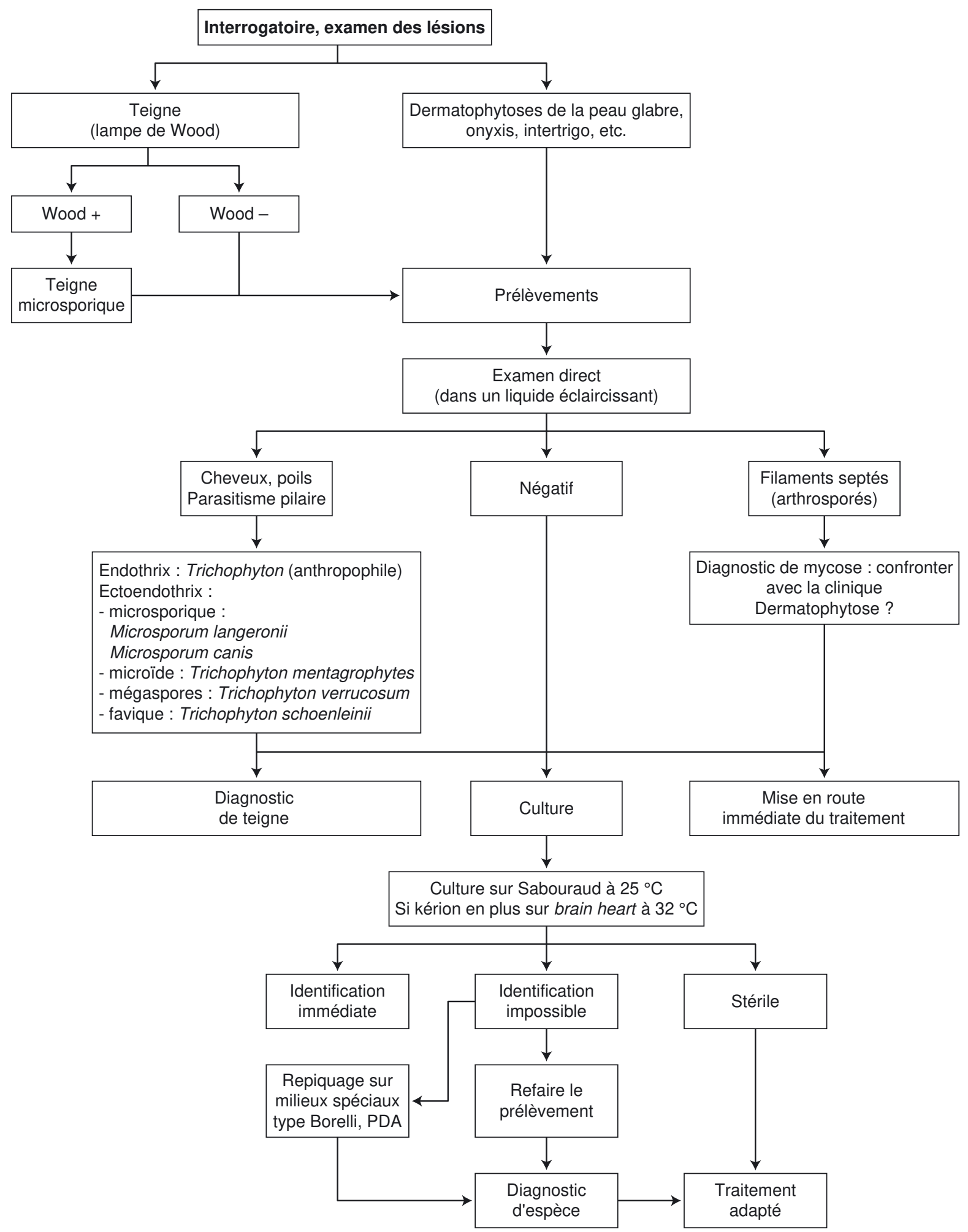

Figure 5. Arbre décisionnel. Démarche diagnostique d'un dermatophyte au laboratoire. PDA : milieu pomme de terre-carotte.

révéler négatif alors que la culture, dont la réponse est plus tardive, est positive. Avec ces résultats faussement négatifs au direct, la biopsie de l'ongle a toute sa valeur pour confirmer rapidement le diagnostic d'une onychomycose.

Il convient de prélever un fragment d'ongle de quelques millimètres et de l'inclure directement en paraffine sans fixation préalable (méthode d'Achten). Les coupes de 10 à $20 \mu \mathrm{m}$ d'épaisseur sont colorées à l'acide périodique Schiff (PAS) ou au Gomori-Grocott permettant, en cas de positivité, de mettre en évidence les filaments mycéliens. L'examen microscopique de ces coupes peut distinguer parfois les moisissures contaminant la surface unguéale des dermatophytes ou des moisissures qui parasitent toute l'épaisseur de l'ongle. De même, l'aspect morphologique des structures fongiques observé peut permettre dans certains cas de distinguer les filaments de dermatophytes souvent longs, rectilignes, septés et d'un calibre régulier, de ceux des moisissures, au contraire d'aspect plus irrégulier.

\section{Cultures}

Les produits pathologiques (fragments de cheveux, d'ongles, de poils et squames cutanées) sont ensemencés sur les milieux usités en mycologie. 


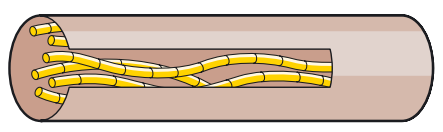

ENC

A

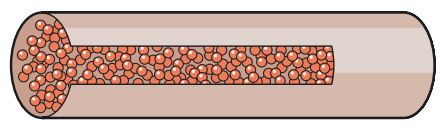

EMC

B

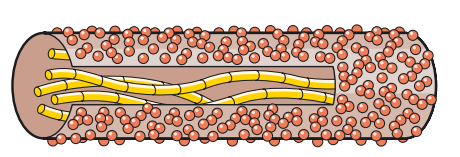

EMC

C ENC

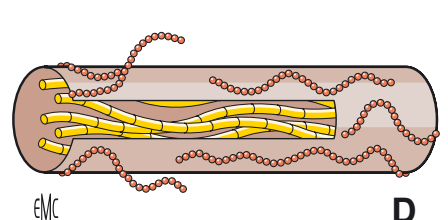

D

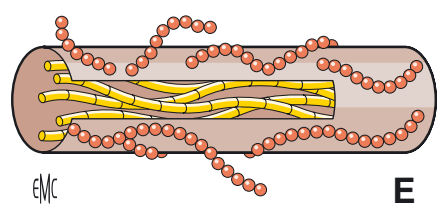

Figure 6. Différents types de parasitisme pilaire par les dermatophytes. A. Type favique (Wood+). Trichophyton schoenleinii.

B. Type endothrix (Wood-). Trichophyton tonsurans, Trichophyton violaceum, Trichophyton soudanense.

C. Type ectoendothrix (Wood+) microsporique. Microsporum canis, Microsporum langeronii, Microsporum ferrugineum.

D. Type ectoendothrix (Wood-) microïde. Trichophyton mentagrophytes, Trichophyton erinacei.

E. Type ectoendothrix (Wood-) mégaspore. Trichophyton verrucosum.

Le milieu d'isolement est celui de Sabouraud, ce dernier est additionné d'un antibiotique et de cycloheximide qui inhibe la pousse de moisissures issues du revêtement cutané. Devant des cultures stériles, un repiquage sur des milieux sélectifs peut être proposé. Le choix de ces milieux dépend de la pratique du laboratoire, le Sabouraud dilué (milieu de Takashio), le milieu de Baxter, le milieu au malt et celui au lactrimel de Borelli sont les plus utilisés. D'autres milieux "maisons » non commercialisés sont aussi usités (milieu pomme de terre-carotte [PDA], pomme de terre-glucosé, etc.). En cas de suspicion de T. verrucosum, agent de teignes ou de lésions inflammatoires, le milieu brainheart infusion (BHI), incubé à $32^{\circ} \mathrm{C}$, peut être proposé d'emblée. Le milieu peptoné à $3 \%$ permet de différencier $M$. persicolor qui devient rose en 8 jours de $T$. mentagrophytes qui donne une culture blanche.

En règle générale, les cultures (en tube ou en boîte) sont incubées à $25-30{ }^{\circ} \mathrm{C}$ pendant un minimum de 4 semaines. Elles sont observées 2 à 3 fois par semaine jusqu'à l'apparition d'une culture identifiable.

Le diagnostic mycologique repose sur des critères culturaux macro- et microscopique mais on tient beaucoup compte de l'examen direct (surtout en cas de parasitisme pilaire) et aussi de la clinique et de l'épidémiologie pour confronter le résultat des cultures au site du prélèvement. Pour plus de détails, il convient de se reporter aux ouvrages de référence ${ }^{[3,58]}$.

\section{Apport de la biologie moléculaire ${ }^{[64-72]}$}

Durant ces dernières années, les approches génomiques ont démontré leur intérêt d'une part pour résoudre certains problèmes de taxinomie et d'autre part pour parfaire l'identification d'une espèce. Concernant les dermatophytes, le diagnostic morphologique montre aussi ses limites du fait des cultures qui sont parfois longues ( 2 à 4 semaines peuvent être nécessaires), nécessitant des repiquages, du temps et un personnel bien formé. Il est donc logique que les techniques moléculaires puissent suppléer aux insuffisances du diagnostic morphologique.

Plusieurs méthodes sont proposées [62-64, 66-69] :

- l'étude du polymorphisme de longueur des fragments de restriction enzymatique (RFLP, restriction fragment length polymorphism) de l'acide désoxyribonucléique (ADN) mitochondrial ;

- le séquençage du gène codant pour une enzyme impliquée dans la synthèse de la chitine (chitine synthétase) ;
- le séquençage de la région ITS (région transcrite mais non traduite) de l'ADN codant pour l'acide ribonucléique (ARN) ribosomique ;

- des techniques de polymerase chain reaction (PCR) permettant l'identification de Trichophyton et de Microsporum.

Des études font état de l'utilisation de la PCR pour l'identification rapide des principales espèces, notamment celles impliquées dans les onychopathies. À titre d'exemple, une PCR rapide (5 heures) permet l'identification de T. rubrum ${ }^{[71]}$. Plus récemment, des tests PCR ont été proposés pour $M$. canis, $M$. audouinii, T. rubrum et E. floccosum [72]. D'autres tests sont utilisés pour le dépistage direct des dermatophytes dans les échantillons prélevés [67]. Toutes ces techniques sont encore expérimentales, non validées, coûteuses, de ce fait peu utilisées en dehors de quelques laboratoires de référence.

Un kit spécifique commercialisé pour la recherche de dermatophytes dans l'ongle (kit OnychoDiag ${ }^{\circledR}$ ) utilisant une méthode rapide d'extraction de l'ADN du champignon et une amplification par PCR est disponible, mais l'identification de l'espèce n'est pas possible, la réponse propose «présence ou absence » de dermatophytes. L'absence d'identification précise de l'espèce et des interprétations erronées dues à la présence de dermatophytes telluriques non pathogènes ou en situation de simple « colonisateur » limitent l'utilisation de cette méthode.

\section{Antifongigramme}

L'antifongigramme n'est pas nécessaire pour les dermatophytes, il n'y a pas de résistance rapportée à ce jour.

\section{Thérapeutique des dermatophytoses et prévention ${ }^{[73-79]}$}

\section{Antifongiques utilisés actifs sur les dermatophytes}

\section{Antifongiques à usage local}

\section{Dérivés azolés}

Leur cible principale est l'ergostérol membranaire composant l'essentiel de la paroi fongique, ils sont surtout fongistatiques, de nombreuses molécules sont utilisées :

- bifonazole (Amycor ${ }^{\circledR}$, crème $1 \%$, dilution $1 \%$, Amycor onychoset $^{\circledR}$, avec pommade à l'urée $\left.1 \%\right)$;

- éconazole (Pévaryl ${ }^{\circledR}$ lait dermique $1 \%$, crème dermique $1 \%$, poudre, spray $1 \%$, Éconazole ${ }^{\circledR}$ ou GNR ${ }^{\circledR}$ en crème poudre solution à $1 \%$ ) ;

- isoconazole (Fazol ${ }^{\circledR}$, crème, poudre et lotion à $\left.2 \%\right)$;

- fenticonazole (Lomexin ${ }^{\circledR}$, crème à $2 \%$ ) ;

- kétoconazole (Ketoderm ${ }^{\circledR}$, crème à $1 \%$ );

- miconazole (Daktarin ${ }^{\circledR}$, gel dermique, lotion, poudre à $2 \%$ ) ;

- omoconazole (Fongamil ${ }^{\circledR}$, crème, poudre, solution à $1 \%$ ) ;

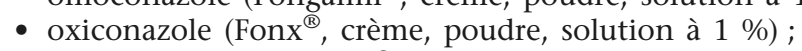

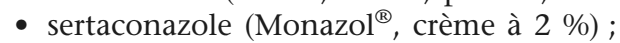

- sulconazole ( $\mathrm{Myk}^{\circledR}, 1 \%$, crème, solution, poudre) ;

- tioconazole (Trosyd ${ }^{\circledR}$, crème à $1 \%$ ).

\section{Tolnaftate}

Il existe sous forme de crème et lotion à $1 \%$ (Sporiline $\left.{ }^{\circledR}\right)$.

\section{Allylamines}

Elles agissent aussi sur la paroi en la rendant perméable et de ce fait assurant la mort du champignon : terbinafine (Lamisil ${ }^{\circledR}$ crème, solution à $1 \%$, Lamisil dermagel ${ }^{\circledR}$, gel à $1 \%$, Lamisilate $^{\circledR}$, crème $1 \%$, Terbinafine Biogaran ${ }^{\circledR}$, crème $1 \%$ ).

\section{Morpholine}

Elle est active aussi sur la paroi du champignon : amorolfine (Locéryl ${ }^{\circledR}$ solution filmogène à $5 \%$ ). 
Tableau 1.

Pharmacocinétique et interactions médicamenteuses des principaux antidermatophytes à usage systémique (d'après [79]).

\begin{tabular}{|c|c|c|}
\hline Molécules & Pharmacocinétique & Principales interactions médicamenteuses \\
\hline Griséofulvine & $\begin{array}{l}\text { Absorption améliorée si prise au cours des repas avec les graisses en } \\
\text { particulier } \\
\text { Métabolisation hépatique en un dérivé inactif } \\
\text { Passage transplacentaire } \\
\text { Élimination fécale }\end{array}$ & $\begin{array}{l}\text { Inducteur enzymatique du CYP3A4 } \\
\text { (substrats : antihistaminiques H1 non sédatifs [astémizole], } \\
\text { statines, antiviraux [névirapine]) }\end{array}$ \\
\hline Terbinafine & $\begin{array}{l}\text { Absorption augmentée si prise effectuée au cours du repas } \\
\text { Passage dans le lait et la barrière hématoencéphalique } \\
\text { Forte diffusion unguéale et cutanée } \\
\text { Métabolisation hépatique en dérivés inactifs } \\
\text { Élimination urinaire }\end{array}$ & $\begin{array}{l}\text { Inhibiteur enzymatique du CYP2D6 (substrats : tramadol, codéine, } \\
\text { lidocaïne) }\end{array}$ \\
\hline Kétoconazole & $\begin{array}{l}\text { Absorption améliorée au cours du repas (diminuée si prise avec } \\
\text { antiacides) } \\
\text { Pas de passage méningé } \\
\text { Métabolisation hépatique } \\
\text { Élimination fécale majoritaire }\end{array}$ & Inhibiteur enzymatique du CYP3A4 \\
\hline
\end{tabular}

Tableau 2.

Contre-indications et principaux effets indésirables de la griséofulvine et de la terbinafine ( $d^{\prime}$ après $\left.{ }^{[79]}\right)$.

\begin{tabular}{|c|c|c|}
\hline Molécules & Contre-indications & Principaux effets indésirables \\
\hline \multirow[t]{3}{*}{ Griséofulvine } & Porphyrie hépatique & En général bien tolérée \\
\hline & Hypersensibilité & Manifestations neurologiques : céphalées surtout \\
\hline & Lupus érythémateux disséminé & $\begin{array}{l}\text { Troubles gastro-intestinaux : anorexie, nausées, diarrhée, perturbation du goût } \\
\text { Photosensibilisation }\end{array}$ \\
\hline \multirow[t]{3}{*}{ Terbinafine } & Insuffisance hépatique et rénale sévère & Troubles digestifs : perte de l'appétit, nausées, douleurs abdominales, diarrhée \\
\hline & Hypersensibilité & Réactions cutanées (éruption, urticaire) non graves \\
\hline & Allaitement & Perte partielle ou totale du goût \\
\hline
\end{tabular}

\section{Hydroxypyridone}

Sa principale cible est le métabolisme cellulaire du dermatophyte :

- ciclopiroxolamine (Mycoster ${ }^{\circledR}$ crème, solution, poudre solution à $1 \%)$;

- ciclopirox $\left(\right.$ Mycoster $^{\circledR}$ solution filmogène à $8 \%$ ) ou Onytec ${ }^{\circledR}$ (ciclopirox $80 \mathrm{mg} / \mathrm{g}$ ).

Acide undécylénique, acides aliphatiques

Mycodécyl $^{\circledR}$, pommade, poudre et solution à $10 \%$.

\section{Antifongiques par voie générale}

En pratique courante trois molécules antifongiques antidermatophytiques sont proposées :

- la griséofulvine : (Griséfuline ${ }^{\circledR}$, cp à 250 et $500 \mathrm{mg}$ ) ;

- la terbinafine : $\left(\right.$ Lamisil $^{\circledR} \mathrm{cp}$ à $250 \mathrm{mg}$, Fungster ${ }^{\circledR} \mathrm{cp}$ à $250 \mathrm{mg}$ ) ;

- le kétoconazole : $\left(\right.$ Nizoral $^{\circledR} \mathrm{cp}$ à $200 \mathrm{mg}$ ).

Leurs pharmacocinétiques, interactions médicamenteuses, effets indésirables et contre-indications sont résumés dans les Tableaux 1 et 2 .

La durée des traitements par voie générale dépend de la localisation et de l'étendue des lésions.

\section{Thérapeutiques alternatives ${ }^{[80]}$}

Des thérapeutiques antifongiques alternatives sont proposées par certains, compte tenu de l'engouement actuel pour les produits naturels et l'échec parfois des thérapeutiques conventionnelles.

\section{Aromathérapie et phytothérapie}

Les huiles essentielles de thym, d'arbre à thé, le bulbe d'ail, la feuille de henné ne présentent aucune autorisation de mise sur le marché (AMM) en France dans le cadre d'un traitement d'une dermatomycose, il n'y a pas d'étude comparative avec un quelconque topique. Néanmoins des préparations sont proposées. Par exemple les huiles essentielles (Thymus vulgaris et Melaleuca alternifolia) sont diluées dans une base neutre (huile d'amande douce, de noisette par exemple) dans les proportions suivantes : $1 / 10^{\mathrm{e}}$ d'huile essentielle dans $9 / 10^{\mathrm{e}}$ d'huile végétale ou 3 à 5 gouttes d'huile essentielle dans $10 \mathrm{ml}$ d'huile neutre. Ensuite elles sont appliquées et directement frottées sur la zone à traiter à l'aide d'une compresse ou d'un coton-tige. L'indication d'une huile essentielle dans les espaces interdigitaux est d'éviter les fissures et la macération.

En phytothérapie aucun essai probant ne démontre la supériorité de ces substances naturelles vis-à-vis des traitements conventionnels.

\section{Homéopathie}

Différentes souches homéopathiques: Arsenicum iodatum, Berberis vulgaris, Graphites, Psorinum, Sépia officinalis Graphites, Sulfures Psorinum, Silicea, Thuya sont utilisées. Ces thérapeutiques, qui ont l'avantage de ne pas présenter d'effets indésirables, ni de contre-indication, sont prescrites sous la responsabilité des médecins homéopathes. Elles ne sont toutefois pas évaluées.

\section{Indications générales}

\section{Teignes du cuir chevelu}

On utilise principalement en première intention chez l'enfant la griséofulvine per os à raison de $20 \mathrm{mg} / \mathrm{kg} / \mathrm{j}$ pendant une durée de 6 à 8 semaines associée à un traitement local (azolés le plus souvent). En cas de teigne zoophile à $M$. canis les doses peuvent être augmentées jusqu'à $25 \mathrm{mg} / \mathrm{kg}$. Les comprimés sont écrasés dans un peu de liquide et avalés avec un aliment gras (type Nutella ${ }^{\circledR}$ ) pour faciliter l'absorption. La griséofulvine peut être remplacée par le kétoconazole $(200 \mathrm{mg} / \mathrm{j}$ chez l'adulte ou 
$7 \mathrm{mg} / \mathrm{kg} / \mathrm{j}$ chez l'enfant) ou la terbinafine $(250 \mathrm{mg} / \mathrm{j}$, réservée à l'adulte), à condition de s'assurer dans tous les cas de l'intégrité des fonctions hépatiques, une surveillance mensuelle de ces dernières est conseillée. En cas de teignes inflammatoires ou kérions, une corticothérapie par voie générale n'est justifiée que si elle est très limitée dans le temps (pour soulager la douleur) et en association avec le traitement antifongique. La griséofulvine à dose plus élevée $(25 \mathrm{mg} / \mathrm{kg} / \mathrm{j})$ a des vertus antiinflammatoires, certains auteurs la préconisent pour éviter l'utilisation intempestive des corticoïdes. D'autres molécules antifongiques peuvent être utilisées dans les teignes du cuir chevelu, il s'agit du fluconazole ou de l'itraconazole pendant 4 à 6 semaines mais elles n'ont pas l'AMM en France.

Aucun antifongique par voie générale n'est autorisé chez la femme enceinte et chez le nourrisson de moins de 1 an. Quel que soit le type de teigne (sèches, inflammatoires) un traitement local doit être institué dès la connaissance de la positivité de l'examen direct pour stopper tout risque éventuel de contamination dans l'entourage.

Des azolés locaux sont appliqués (crèmes, lotions), en cas de lésions très croûteuses on utilise volontiers une solution huileuse de tolnaftate, un shampooing antifongique (Keto$\operatorname{derm}^{\circledR}$ ) deux fois par semaine est aussi recommandé, en revanche l'utilisation de corticoïdes locaux est déconseillée.

Une enquête épidémiologique (recherche des sujets contacts dans l'entourage immédiat) est aussi nécessaire pour éviter une éventuelle rechute, tout comme l'éviction scolaire pour les teignes anthropophiles. Cependant cette éviction peut être levée s'il y a présentation d'un certificat médical attestant d'une consultation et de la prescription d'un traitement adapté (Guide des conduites à tenir en cas de maladies transmissibles dans une collectivité d'enfants. Conseil supérieur d'hygiène publique de France : séance du 14 mars 2003). La désinfection des peignes, brosses, tondeuses, bonnets à l'aide de poudre antifongique est nécessaire pour éviter les récidives.

\section{Dermatophytoses de la peau glabre et intertrigos}

On préconise en première intention, sauf en cas de lésions très étendues ou multiples, un traitement par un topique antifongique local. Le choix crème, lotion ou gel dépend de l'aspect plus ou moins suintant de la lésion. L'application du produit doit être quotidienne après la toilette, la durée dépend de l'importance des lésions et de l'espèce en cause. Le traitement, surtout dans les plis, doit être continué au moins pendant 3 semaines, même après la guérison clinique.

En cas d'atteintes étendues des poils (folliculites), de lésions inflammatoires, on peut utiliser chez l'adulte la terbinafine à raison de $250 \mathrm{mg} / \mathrm{j} / 2$ semaines, et la griséofulvine pendant 4 semaines environ chez l'enfant ou chez l'adulte en cas de lésions inflammatoires.

La prévention des intertrigos, en particulier des espaces interdigito-plantaires, passe par des mesures d'hygiène individuelles et collectives.

\section{Paumes des mains et plantes des pieds}

L'application d'un topique azolé ou de la terbinafine en crème ou encore de la ciclopiroxolamine est dans un premier temps conseillée pendant 3 semaines à 1 mois, en association à un traitement (terbinafine chez l'adulte) par voie générale.

\section{Onyxis à dermatophytes}

Deux situations sont à envisager.

\section{Sans atteinte matricielle de l'ongle}

Le traitement peut rester local. Les préparations galéniques antifongiques en vernis (amorolfine, ciclopirox) sont les plus indiquées. Elles sont appliquées une fois par semaine pour le premier et quotidiennement pour le second et ceci pendant une durée de 3 à 6 mois selon l'étendue des lésions. L'avulsion chimique de l'ongle peut être réalisée avec une association azolés (bifonazole) et urée, tout comme l'élimination mécanique des zones unguéales réalisée par le pédicure. En cas d'onycholyse le traitement local reste inefficace. En général le traitement doit être poursuivi au-delà de la repousse de l'ongle sain. Un traitement concomitant des espaces inter-digito-plantaires (ou palmaires) est aussi nécessaire pour éviter toute réinfestation.

En cas d'atteinte plus importante, un traitement par voie générale peut être institué, il fait appel à la terbinafine à raison de 1 comprimé de $250 \mathrm{mg} / \mathrm{j}$ pendant 3 à 6 mois pour les ongles des pieds et de 6 semaines à 3 mois pour ceux des mains.

\section{Avec atteinte matricielle}

$\mathrm{Au}$ traitement local de l'ongle précédemment cité, il est nécessaire d'associer un traitement par voie générale. La terbinafine est la molécule de choix. En cas d'intolérance et de contre-indication le kétoconazole peut être utilisé à condition de s'assurer de l'intégrité des fonctions hépatiques. Les triazolés (fluconazole, itraconazole) sont actifs dans les onychomycoses à dermatophytes mais ils n'ont pas d'AMM en France dans cette indication.

Dans tous les cas, comme pour l'atteinte précédente, la suppression du maximum d'ongles lésés par meulage et découpage avec pince, ou par traitement chimique (bifonazole-urée) est souhaitable.

Les échecs thérapeutiques sont cependant fréquents, ils peuvent être dus à :

- une mauvaise diffusion de l'antifongique par voie systémique dans les tissus unguéaux lésés à cause de l'hyperkératose ou en raison d'une onycholyse ou décollement de l'ongle qui empêche la pénétration du produit actif ;

- un traitement interrompu trop tôt (la vitesse de pousse unguéale est lente et elle ralentit fortement avec l'âge) ;

- une atteinte trop importante de l'ongle ;

- une recontamination, d'où la nécessité de traiter les espaces interdigitaux associés (voir mesures de prophylaxies individuelles) :

- la non-prise en compte d'un terrain favorisant (immunodépression) ;

- la possibilité d'une atteinte par une moisissure rebelle au traitement ou d'une autre étiologie de dystrophie unguéale (psoriasis, lichen).

\section{Prévention du « pied d'athlète " (intertrigos, onyxis, atteinte plantaire)}

La prévention collective est du ressort des collectivités, bien qu'il n'y ait pas de norme AFNOR (drainage des eaux de douche, désinfection quotidienne ou biquotidienne des sols des piscines, douches, toilettes et vestiaires à l'eau de Javel diluée).

La prévention individuelle conseille aux utilisateurs de ces aires de bains, de bien s'essuyer et sécher les pieds et les espaces interdigitaux après la douche suivant la pratique sportive. Il convient aussi de décontaminer les chaussons et les chaussures de sports (poudres antifongiques), de se couper les ongles courts et pour les sportifs assidus ou professionnels exposés (maîtresnageurs) d'appliquer régulièrement une fois par semaine un topique azolé (éconazole, bifonazole) ou mensuellement (topique terbinafine) pour prévenir la récidive d'une dermatophytose plantaire ou interdigitale. Enfin, le lavage en machine à $60{ }^{\circ} \mathrm{C}$ des vêtements de sport (chemise, chaussettes, slip, short de sport ou de bain) est préconisé.

\section{Cas particuliers}

Les intertrigos récidivants, les pachydermies des paumes et des plantes, les folliculites nécessitent en plus des traitements locaux des traitements par voie générale par griséofulvine, terbinafine ou kétoconazole.

Le choix de la molécule et sa durée de 3 à 4 semaines selon l'étendue des lésions dépendent aussi de la tolérance au produit. Parfois, la connaissance de l'espèce en cause est utile au thérapeute pour guider son choix. Ainsi, une dermatophytose étendue à T. rubrum nécessite un traitement prolongé par voie générale tandis qu'un intertrigo des plis inguinaux à $E$. floccosum peut être guéri efficacement avec un simple traitement local. 
De même l'arrêt de la corticothérapie sur des lésions cutanées d'allure eczématiforme où a été isolé Microsporum praecox peut suffire avec une simple application pendant 8 jours d'un topique antifongique sur les lésions.

\section{Conclusion}

Les dermatophytes sont des champignons filamenteux microscopiques bien adaptés à la kératine humaine et animale. Les lésions qu'ils provoquent sont en général bénignes mais elles évoluent sur un mode chronique et volontiers récidivant, simulant d'autres affections dermatologiques. L'identification du dermatophyte responsable est obligatoire avant de débuter un traitement spécifique, particulièrement dans les formes cutanées étendues, les teignes et les atteintes unguéales. La prévention, facilitée par la connaissance du champignon (anthropophile, zoophile ou tellurique), repose sur la maîtrise (dépistage, traitement) de la source de la contamination.

\section{6 Points forts}

Les dermatophytoses sont les mycoses cutanées les plus fréquentes.

Les dermatophytes sont des champignons filamenteux cosmopolites. Appartenant à trois genres, Microsporum, Trichophyton et Epidermophyton, ils affectionnent particulièrement la kératine humaine (peau, phanères) et animale. Ils colonisent le revêtement cutané et produisent souvent des lésions cliniques variées (dermatophytoses, intertrigos, teignes, folliculites, onyxis, etc.).

Leur origine est le sol (espèces telluriques), les études phylogéniques ont montré qu'ils se sont adaptés à I'animal (espèces zoophiles) puis à I'homme (espèces anthropophiles). Seules les espèces anthropophiles sont contagieuses d'homme à homme, d'où l'intérêt du diagnostic mycologique qui confirme le diagnostic et précise l'espèce en cause.

Le prélèvement à visée mycologique est obligatoire avant tout traitement local ou général, surtout lorsqu'il s'agit d'un traitement per os, prolongé, indispensable, notamment en cas d'atteinte des phanères.

Les auteurs dédient cette mise au point au Dr Guy Badillet, leur professeur, guide et ami, aujourd'hui disparu, qui a porté haut et fort la Mycologie française.

\section{Références}

[1] Chabasse D, Bouchara JP, de Gentile L, Brun S, Cimon B, Penn P. Les dermatophytes. Cah Form Bioforma 2004(n 37) (159p).

[2] Chabasse D. Les dermatophytes : d'où viennent-t-ils? Comment sontt-ils devenus des parasites. J Med Mycol 2008;18:27-37.

[3] Badillet G. Dermatophyties et Dermatophytes - Atlas Clinique et Biologique. Paris: Varia; 1991.

[4] Bormann AM, Campehell CK, Fraser M, Johnson EM. Analysis of dermatophytes species isolated In the British Iles between 1980 and 2005 and review of worldwide dermatophytes trends over the last three decades. Med Mycol 2007;45:131-41.

[5] Rippon JW. Forty fours years of dermatophytes in Chicago clinic (1944-1988). Mycopathologia 1992;119:25-8.

[6] Feuilhade de Chauvin M, Lacroix C. Epidémiologie des teignes du cuir chevelu. Presse Med 2001;30:499-500.

[7] Cafarchia C, Romito D, Capelli G, Guillot J, Otranto D. Isolation of Microsporum canis from the hair coat of pet dogs and cats belonging to owners diagnosed with M canis, tinea corporis. Vet Dermatol 2006;17: 327-31.
[8] Vigué-Vallanet C, Savaglio N, Piat C, Tourte-Scheffer C Epidémiologie des teignes à Microsporum canis en région parisienne. Ann Dermatol Venereol 1997;124:696-9.

[9] Weill FX, Bernier V, Malleville J, Amathieux V, Claverie F, et al. Epidémie de teignes du cuir chevelu à Microsporum audouinii var langeronii dans un groupe scolaire Bordelais. J Mycol Med 1999;9: 52-6.

[10] Hay RJ, Robles W, Midgley G, Moore MK. European Confederation of Medical Mycology Working Party on Tinea Capitis. Tinea capitis in Europe: new perspective on an old problem. J Eur Acad Dermatol Venereol 2001;15:229-33.

[11] Arnow PM, Houchins SG, Pugliese G. An outbreack of tinea corporis in hospital caused by patient with Trichophyton tonsurans infection. Pediatr Infect Dis J 1991;10:355-9.

[12] Fuller LC, Child FC, Higgins EM. Tinea capitis in south-east London: an outbreak of Trichophyton tonsurans infection. Br J Dermatol 1997; 136:132-48.

[13] Stroba J, Olson-Burgess C, Preuett B, Abdell-Rahman SM. A large outbreak of Trichophyton tonsurans among health care workers in a pediatric hospital. Am J Infect Control 2009;37:43-8.

[14] Chabasse D, Contet-Audonneau N. Mycoses superficielles à Dermatophytes observées en France métropolitaine, Parasitoses et Mycoses courantes de la peau et des phanères. Coordinateurs D. Chabasse et E. Caumes, Guides Médi/Bio. Elsevier; 2003.

[15] Feuilhade de Chauvin M. Les onychomycoses. Rev Prat 2000;50: 2223-30.

[16] Chabasse D. Peut-on chiffrer la fréquence des onychomycoses? Ann Dermatol Venereol 2003;130:1222-30.

[17] Foulet F, Curvale-Fauchet N, Cremer G, Pérignon A, Bourée P, Estrangin E, et al. Epidémiologie des teignes du cuir chevelu. Etude rétrospective sur ans dans 3 centres hospitaliers du Val de Marne. Presse Med 2006;35:1231-4.

[18] Lacroix C, Benderdouche M, Haman S, Derouin F, Feuilhade de Chauvin M. Trichophyton tonsurans : un dermatophyte particulièrement contagieux ? Journées dermatologiques de Paris; 2001, communication 151 .

[19] Viguié-Vallanet C, Serre M, Masliah L, Tourte-Schaefer C. Epidémie de teignes à Trichophyton tonsurans dans une école maternelle de la région parisienne. Ann Dermatol Venereol 2005;132:432-8.

[20] Le Guyadec T, Le Guyadec J, Herve V, Soler C, Che D, Schmoor P. Prise en charge des teignes : enquêtes auprès des médecins scolaires et des dermato-praticiens. Ann Dermatol Venereol 2001;128:725-7.

[21] Chabasse D. Epidémiologie et étiologie des onychomycoses. In: Baran R, Pierrard GE, editors. Onychomycoses. Paris: Masson; 2004. p. 1-35.

[22] Pihet M, Bourgeois H, Maziére JY, Berlioz-Arthaud A, Bouchara JP, Chabasse D. Isolation of Trichopyton concentrichum from chronic cutaneous lesions in patients from the Salomons islands. Trans $R$ Soc Trop Med Hyg 2008;102:389-93.

[23] Stiller MJ, Klein WP, Dorman RI, Rosenthal S. Tinea corporis gladatorium: an epidemic of Trichophyton tonsurans in students wrestlers. J Am Acad Dermatol 1992;27:632-3.

[24] Poisson DM, Rousseau D, Defo D, Esteve E. Outbreak of Tinea corporis gladiatorum, a fungal skin infection due to Trichophyton tonsurans, in a French high level judo team. Euro Surveil 2005;10: 187-90

[25] Esteve E, Rousseau D, Defo D, Poisson DM. Epidémie de trichophyties cutanées chez les judokas du pôle France d'Orléans : septembre 2004 juin 2005. Ann Dermatol Venereol 2006;133:525-9.

[26] Shiraki Y, Hiruma M, Hirose N, Ikeda S. Commonly affected body sites in 92 Japanese combat sports participants with Trichophyton tonsurans infection. Mycoses 2009;52:339-42.

[27] Chabasse D, Cimon B, de Gentile L, Bouchara B. Les mycoses transmises de l'animal à 1'homme. Rev Fr Lab 1991;228:77-81.

[28] Mossovitch M, Mossovitch B, Alkan M. Nosocomial dermatophytosis caused by Microsporum canis in a newborn department. Infect Contracept 1986;7:593-5.

[29] Shah PC, Kradjen S, Kane J, Summerbell RC. Tinea corporis caused by Microsporum canis report of nosocomial outbreack. Eur J Epidemiol 1998;4:33-8

[30] Monkassa B, Vandemeulebroucke E, Redlinski S, Jousserand P, Poujade F. Dermatophytes et teignes du cuir chevelu dans la banlieue nord de Paris. J Mycol Med 2000;10:207-9. 
[31] Rispail P, Lachaud L, Gayvallet-Montredon N, Jarry DT, Jarry DM. Six cent vingt-cinq cas de teignes du cuir chevelu à Montpellier (France). J Mycol Med 1999;9:68-71.

[32] Aoun K, Bouratbine A, Mokni M, Chatti S, Ben Ismail R, Ben Osman A. Teignes du cuir chevelu causées par Trichophyton rubrum chez deux enfants atteints de dermatophyties extensives. J Mycol Med 1998;8:200-2.

[33] El Euch D, Mokni Cherif F, Sellami A, Azaiz MI, Ben Osman Dhahri A. Les teignes du cuir chevelu observées à Tunis de 1985 à 1998 : à propos de 1222 cas. J Mycol Med 2001;11:87-91.

[34] Ouaffak L, Gati A, Lyagoubi M. Les teignes du cuir chevelu dans les écoles primaires de Khemisset (Maroc). J Mycol Med 2001;11:181-4.

[35] Makni F, Neji S, Sellami A, Cheikrouhou F, Sellami H, Marrekchi S, et al. Les teignes du cuir chevelu dans la région de Sfax (Tunisie). J Mycol Med 2008;18:162-5.

[36] Chabasse D, Contet-Audonneau N, Dunand J. Dermatoses superficielles tropicales (à l'exception des teignes). In: Chabasse D, Develoux M, editors. Mycoses d'importation. Paris: Guide Médi/Bio, Elsevier; 2003. p. 17-29.

[37] Baran R, Chabasse D, Feuilhade de Chauvin M. Les onychomycoses II. Approche diagnostique. J Mycol Med 2001;1:5-13.

[38] Baran R, Pierrard GE. Onychomycoses. Paris: Masson; 2004.

[39] Tosti A, Baran R, Piraccini BM, Fanti A. Endonyx onychomycosis: a new modality of nail invasion by dermatophytes. Acta Derm Venereol 1999;79:52-5.

[40] Bardazzi F, Neri I, Marzaduri S, Landi C, D'Antuono A. Microsporum canis infection of the penis. Genitourin Med 1997;73:759.

[41] Porro AM, Yoshioka MC, Kaminski SK, Pameira MC, Fischman O, Alchorne M. Disseminated dermatophytosis caused by Microsporum gypseum in two patients with the acquired immunodeficiency syndrome. Mycopathologia 1997;137:9-12.

[42] Cortes Franco R. Deep dermatophytosis in post transplant recipient. Int J Dermatol 2001;40:363-4.

[43] Erbagci Z. Deep dermatophytoses in association with atopy and diabetes mellitus: Majocchi's granuloma tricophyticum or dermatophytic pseudomycetoma? Mycopathologia 2001;154:163-9.

[44] Chastain MA, Reed RJ, Pankey GA. Deep dermatophytosis: report of 2 cases and review of the literature. Cutis 2001;67:457-62.

[45] Zaias N, Rebell G. Clinical and mycological status of the Trichophyton mentagrophytes (interdigitale) syndrome of chronic dermatophytosis of the skin and nails. Int J Dermatol 2003;42:779-88.

[46] Nir-Paz R, Elinaz H, Pierard GE. Deep infection by Trichophyton rubrum in an immunocompromised patient. J Clin Microbiol 2003;41: 5298-301.

[47] Yamamoto T, Nishoska K. Deep dermatophytosis during topical tacrolimus therapie for psoriasis. Acta Derm Venereol 2003;83:291-2.

[48] Hay RJ, Baran R. Deep dermatophytosis: rare infections or common, but unrecognised, complications of lymphatic spread? Curr Opin Infect Dis 2004;17:77-9.

[49] Lowther AL, Somani AK, Camouse M, Florentino FT, Somach SC. Invasive Trichophyton rubrum infection occurring with infliximad and long-term prednisone treatment. J Cut Med Surg 2007;11:84-8.

[50] Marconi VC, Kradin R, Marty FM, Hospenthal DR, Kotton CN. Disseminated dermatophytosis in a patient with hereditary hemochromatosis and hepatic cirrhosis: case report and review of the literature. Med Mycol 2010;48:518-22.

[51] Boudghène-Stambouli $O$, Mèrad-Boudia A. La maladie dermatophytique en Algérie : nouvelle observation et revue de la littérature. Ann Dermatol Venereol 1991;118:17-21.

[52] Boudghène-Stambouli O, Mèrad-Boudia A. Maladie dermatophytique : hyperkératose exubérante avec cornes cutanées. Ann Dermatol Venereol 1998;125:705-7.

[53] Boudghène-Stambouli O, Guelil B, Belbachir A. La teigne : un mode de début de la maladie dermatophytique. Ann Dermatol Venereol 2007; 134:71.

[54] Dib-Lachachi A, Boudghène-Strambouli O, Mankouri A. La maladie dermatophytique : 1959-2009: 50 ans après sa description deux nouvelles observations d'évolution fatales. Ann Dermatol Vénéréol 2009; 136:F58-F199. doit:10.016/j.annder.2008.11.005.

[55] Cheikhrouhou F, Makni F, Ayadi A. La maladie dermatophytique : revue de la littérature. J Mycol Med 2010;20:61-9.

[56] Nzenze-Afene S, Mabika B, Ougoula Gerbex S, Ferly Therizol M, Kombila M. Mycétomes dermatophytiques du cuir chevelu : à propos de deux cas à Microsporum langeronii et revue de la littérature. J Mycol Med 2006;16:42-6.
[57] Hongcharu W, Dwyer P, Gonzales S, Anderson R. Confirmation onychomycosis by in vivo confocal microscopy. J Am Acad Dermatol 2000;42:214-6.

[58] Chabasse D, Contet-Audonneau N. Moisissures dermatophytes, levures. Du prélèvement au diagnostic. Paris: BioMérieux SA Educations; 2008 (189p).

[59] Chabasse D, Pihet M. Les dermatophytes, les difficultés du diagnostic mycologique. Rev Fr Lab 2008;406:29-36.

[60] Robert R, Pihet M. Conventional methods for the diagnosis of dermatophytes. Mycopathologia 2008;166:295-306.

[61] Panasiti V, Borroni RG, Devirgiliis V, Rossi M, Fabbrizio L, Masciangelo R, et al. Comparison of diagnostic methods in the diagnosis of dermatomycoses and onychomycoses. Mycoses 2006;49: 26-9.

[62] Erhard M, Hipler UC, Burmester A, Brakhage AA, Wostemeyer J. Identification of dermatophyte species causing onychmycosis and tinea pedis by MALDI-TOF mass spectrometry. Exp Dermatol 2008;17: 356-61.

[63] Slifkin M, Cumbie R. Congo red as a fluorochrome for the rapid detection of fungi. J Clin Microbiol 1988;26:827-30.

[64] Kambe T. Molecular approaches in the diagnosis of dermatophytosis. Mycopathologia 2008;166:307-17.

[65] Harmsen D, Schwinn A, Brocker EB, Frosch M. Molecular differentiation of dermatophyte fungi. Mycoses 1999;42:67-70.

[66] Liu D, Coloe S, Baird R, Pedersen J. Application of PCR to the identification of dermatophyte fungi. J Med Microbiol 2000;49:493.

[67] Uchida T, Makimura K, Ishihara K, Goto H, Taijiri Y, Okuma M, et al. Comparative study of direct polymerase chain reaction, microscopic examination and culture-based morphological methods for detection and identification of dermatophytes in nail and skin samples. J Dermatol 2009;36:202-8.

[68] Shin JH, Sung JH, Park SJ, Kim JA, Lee JH, Lee DY. Species identification and strain differentiation of dermatophyte fungi using polymerase chain reaction amplification and restriction enzyme analysis. J Am Acad Dermatol 2003;22:857-65.

[69] Ninet B, Jan I, Bontems O, Lechenne B, Jousson O, Panizzon R, et al. Identification of dermatophyte species by $28 \mathrm{~S}$ ribosomal DNA sequencing with a commercial kit. J Clin Microbiol 2003;41:826-30.

[70] Li HC, Bouchara JP, Hsu MM, Barton R, Chang TC. Identification of Dermatophytes by an Oligonucleotide Array. J Clin Microbiol 2007; 45:3160-6.

[71] Brillowska-Dabrowska A, Saunte DM, Arendrup MC. Five-hour diagnosis of dermatophytes nails infections with specific detection of $T$ rubrum. J Clin Microbiol 2007;45:1200-4.

[72] Brillowska-Dabrowska A, Swierkowska A, Saunte DM, Arendrup MC. Diagnostic PCR tests for Microsporum audouinii, M canis, and Trichophyton infections. Med Mycol 2010;48:486-90.

[73] Gupta AK, Adam P, Dlova N, Lynde CW, Aboobaker J, Summerbell RC. Therapeutic options for the treatment of tinea capitis caused by Trichophyton species: griseofulvin versus the new oral antifungal agents, terbinafine, itraconazole, and fluconazole. Pediatr Dermatol 2001;18:433-8.

[74] Gupta AK, Tu LQ. Dermatophytes: diagnostic and treatment. J Am Acad Dermatol 2006;54:1050-5.

[75] Duhard E, Coudiere P, Voisard JJ, Allaert FA. Prise en charge des onychopathies présumées d'origine mycosique en dermatologie libérale. Ann Dermatol Venereol 2006;133:11-5.

[76] Scrivener Y. Onychomycoses, analyse systématique des essais thérapeutiques. Ann Dermatol Venereol 2007;134:17-45.

[77] Groupe de travail de la Société Française de Dermatologie, Recommandations pour la pratique clinique - Onychomycoses : modalités de diagnostic et de prise en charge. Ann Dermatol Venereol 2007;134: 7-16.

[78] Lacroix C, Feuilhade de Chauvin M. Traitements antifongiques. EMC (Elsevier Masson SAS, Paris), Dermatologie, 98-906-A-10, 2008.

[79] Deunieul A, Faure S. Les traitements antifongiques. Actual Pharm 2008;484:14-8.

[80] Derbré S. Emploi de la phytothérapie et de l'aromathérapie en prévention et traitement des dermatomycoses. Actual Pharm 2009;484:19-20.

\section{Pour en savoir plus}

Achten G, Andre J. Techniques de biopsie de l'ongle. Ann Dermatol Venereol 1987; 114:889-92.

Baran R, Hay R, Haneke E, Tosti A. Les Mycoses unguéales, étapes diagnostique et thérapeutique. London: Informa healthcare UK Ltd; 2006.

Campbell CK, Johnson EM, Philpot CM, Warnock DW. Identification of pathogenic fungi. London: Public Health Laboratory Service; 1996. 
Gupta AK, Summerbell RC. Tinea capitis. Med Mycol 2000;38:255-87.

Hadida E, Schousboe A. Aspects de la maladie dermatophytique. Algerie Méd 1959;63:303-37.

Hainer BL. Dermatophyte infections. Am Fam Physician 2003;67:101-8. Hochedez P, Datry A, Caumes E. Mycoses superficielles. EMC (Elsevier Masson SAS, Paris), AKOS (Traité de Médecine), 4-1380, 2007.

Kane J, Summerbell RC, Sigler L, Krajden S, Land G. A clinical guide and laboratory manual of dermatophytes and other filamentous fungi from skin, hair and nails. Star Publishing Company; 1997.

Kac G. Molecular approaches to the study of dermatophytes. Med Mycol 2000;38:329-36.
Lacroix C, Feuilhade de Chauvin M. Teignes du cuir chevelu d'importation observées en France métropolitaine. In: Chabasse D, Develoux M, editors. Mycoses d'importation. Paris: Guide Médi/Bio Elsevier; 2003. p. 3-15.

Sabouraud R. Les teignes. Paris: Masson; 1910 (855p).

Summerbell RC. Trichophyton, Microsporum, Epidermophyton, and agents of superficial mycosis. In: Murray PR, Baron EJ, Jorgensen JH, Pfaller MA, Yolken RH, editors. Manual of clinical microbiology. Washington DC: ASM Press; 2003. p. 1798-819.

Zagnoli A, Chevalier B, Sassolas B. Dermatophyties et dermatophytes. EMC (Elsevier Masson SAS, Paris), Pédiatrie, 4-110-A-10, 2005. 